\title{
TESTEMUÑAS HERÁLDICAS E DOCUMENTAIS DUN FIDALGO LUCENSE: GASPAR LÓPEZ DE VAAMONDE
}

\author{
PABLO S. OTERO PIÑEYRO MASEDA \\ XOSÉ ANTÓN GARCÍA GONZÁLEZ-LEDO \\ CSIC-Xunta de Galicia \\ Instituto de Estudios Gallegos «Padre Sarmiento» ${ }^{1}$
}

\begin{abstract}
Resumo
Estúdase a liña xenealóxica de Gaspar López de Vaamonde, fidalgo da comarca da «Terra Cha» lucense, prestando especial atención a súas vivendas rurais e manifestacións heráldicas, del mesmo e da súa liña sucesoria, comprementado todo elo coas correspondentes ilustracións. Co coñecemento preciso das elites locais de cada intre e logar, contribúiese a ter unha visión máis exacta do que foi o noso pasado común histórico e artístico.
\end{abstract}

\section{Palabras clave}

Fidalguía, Paleografía, Xenealoxía, Heráldica, epigrafía funeraria, Idade Moderna, vida cotián, casas fidalgas, pousas, pazos.

\begin{abstract}
The family tree of Gaspar López de Vaamonde, a nobleman from the Terra Cha region of Lugo, is studied. Special attention is paid to his rural housing and their heraldic signs together with the nobleman himself and his succession line. All is complemented with the corresponding illustrations.

A contribution to a more accurate overview of what was our common historic and artistic past is made thanks to the precise knowledge of the local elite in every time and place.
\end{abstract}

\section{Key Words}

Gentlemanliness, Paleography, Genealogy, Heraldry, funerary epigraphy, Modern Age, daily life, nobleman housing, palaces.

\footnotetext{
${ }^{1}$ Iste traballo é un compremento do proxecto Corpus de epigrafía heráldica y escultura funeraria, medieval gallega, que se desenvolve no Instituto de Estudos Galegos «Padre Sarmiento» (CSICXunta de Galicia) baixo a dirección do Dr. Eduardo Pardo de Guevara y Valdés.

Pablo Santiago Otero Piñeyro Maseda é tamén alumno etapa tese no Dpto. de Historia I da Universidade de Santiago de Compostela.
} 
O obxecto destas páxinas é realizar unha sembranza do fidalgo chairego ${ }^{2}$ Gaspar López de Vaamonde ${ }^{3}$, un de tantos notábeles persoaxes de época moderna que deixou distintas testemuñas artísticas e documentais que non deben ficar no esquencemento. Co coñecemento preciso das elites locais de cada intre e logar, contribúiese a ter unha visión máis exacta do que foi o noso pasado común e do que é a nosa identidade.

\section{DATOS BIOGRÁFICOS}

Poucos datos poden precisarse acerca dos devanceiros de Gaspar López de Vaamonde, dono da hoxe desaparecida Casa Torre de Trobo, si ben polas súas armas pode considerárselle descendente da coñecida estirpe dos Vaamonde ${ }^{4}$.

Informacións documentais do Arquivo do Pazo do Souto (San Fiz de Cerdeiras, Begonte, Lugo) permítenos supoñelo fillo de Pedro López de Vaamonde ${ }^{5}$ e da súa muller Mayor Ares; tamén dedúcese que foi mellorado con diversos bens na parroquia de Santa María de Trobo e seus arredores con gravamen de vínculo e morgado o 5 de outubro de $1577^{6}$. Manuel Vázquez Seijas cita ademáis coma seus ascendentes a Manuel de Vaamonde e a Lope de Vaamonde -que sinala coma fundador da Casa Torre- mais istas informacións ó caresceren de base documental non se poden considerar fiabeis ${ }^{7}$.

\footnotetext{
${ }^{2}$ A comarca lucense da Terra Cha comprende os concellos de Begonte, Guitiriz, Cospeito, Castro de Rei, A Pastoriza, Abadín, Vilalba, Muras e Xermade. V. Mapa Comarcal de Galicia, escala 1:250.000, Madrid, Presidencia: Gabinete de Planificación e desenvolvemento territorial, [1997].

${ }^{3}$ Aínda que oficialmentes recóllese o topónimo «Baamonde» no Nomenclátor de Galicia, os autores prefiren conservar a forma na que aparesce escrita máis habitualmentes na documentación e nos epígrafes, o mesmo que os nomes proprios e apelidos das persoas. V. Nomenclátor de Galicia Toponimia Oficial das provincias, concellos, parroquias e lugares, [s.n.], Xunta de Galicia, [2003], páx. 108.

${ }^{4}$ Posibelmentes sexa descendente de un dos vástagos de dona Mayor de Vaamonde, que casou de primeiras con Vasco Fernández de Párrega, e despois con Fernán Díaz de Ribadeneira. V. a xenealoxía distos persoaxes en Eduardo PARdo De Guevara y VALdés, «Parentesco y Nepotismo. Los arzobispos de Santiago y sus vínculos familiares en los siglos XIV y XV», en Ramón Yzquierdo Perrín (ed.), Los coros de catedrales y monasterios: arte y liturgia. Actas del simposio organizado por la Fundación Pedro barrié de la Maza en A Coruña; 6-9 de septiembre de 1999, A Coruña, Fundación Pedro Barrié de la Maza, 2001, páxs. 90-91.

${ }^{5}$ V. doc. n. ${ }^{\circ} 1$ do Ápendice Documental (en adiane AD). Os autores agradecen as precisións e facilidades dadas por Antonio Fernández-Albalat para a consulta do importante fondo documental de Souto, magoadamentes bastante minguado polo decorrer da Historia.

${ }^{6}$ Os autores agraden estas precisións suxeridas polo investigador lucense Manuel Julio Platero Campo.

${ }^{7}$ Manuel VÁzQuez Seijas, Fortalezas de Lugo y su provincia, Lugo, Imprenta de la Excma. Diputación, 1967, T. IV, páxs. 164 y 167.
} 
A tenor da documentación acadada -recollida no «Apéndice Documental»pódese situar o nascimento de Gaspar hacia o ano 1560, en tanto que o seu falescimento produciríase antre marzal de 1630 e abril de 1633, data na que consta documentalmentes que xa tiña morto ${ }^{8}$.

Suponse que tino alomenos dous irmáns: Blas López de Vaamonde, e Isabel de Vaamonde, a cal casou con Fernando Díaz Ribadeneira, do «coto de Trabado», documentados en 1599 posuíndo bens en San Pedro de Pígara9

O protagonista distas praxinas, Gaspar López de Vaamonde, casou con Constanza Vázquez de Parga; matrimonio que débese datar denantes do mes de febreiro do 1582, pois niste ano aquela intervén xunto ó seu marido na compra de bens en Santiago de Felmil ${ }^{10}$. Os pais de Constanza dotaríana con diversos bens na parroquia de San Pedro de Pígara ${ }^{11}$.

Os fillos diste matrimonio, segundo consta nunha dilixenza de partixas outorgada o 5 de abril de $1633^{12}$ foron os seguintes:

- O Capitán Sebastián de Vaamonde e Parga, que se supón foi mellorado no terzo e quinto, e que herdou os bens da Casa Torre de Trobo. Casou con Ana Rodríguez do Monte de Reigosa, con quen tivo varios fillos, falescendo denantes do $1665^{13}$.

- O Lic. Bartolomé López de Vaamonde e Parga, clérigo, veciño de Santiago de Illán.

- O Lic. Manuel de Vaamonde e Parga, veciño de Betanzos.

- María de Vaamonde, que casou con Antonio López Moro, escribán, veciño do couto do Mato, sendo dotada polo seu pai con alomenos 28 cuartais de pan de renda correspondentes a un foro da terceira parte do lugar da Ponte de Rábade ${ }^{14}$.

\footnotetext{
${ }^{8}$ V. doc. n. ${ }^{\circ} 65$ do AD, outorgado en Trobo.

${ }^{9}$ V. doc. n. ${ }^{\circ} 49$ do AD, outorgado en Saavedra, no que se menciona ós tres irmáns.

${ }^{10}$ V. doc. $\mathrm{n}^{\circ} 2$ do $\mathrm{AD}$.

${ }^{11}$ V. doc. n. ${ }^{\circ} 76$ do AD.

12 V. doc. n. ${ }^{\circ} 65$ do AD, outorgado en Trobo.
}

${ }^{13}$ Antre outros tivo a Constanza Vázquez, que casou ó redor de 1665 con Marcos García e Parga. V. LUGO, Archivo de Gaibor, Inventario de Escrituras del Archivo de Gaibor, Leg. 6, n. ${ }^{\circ}$ 1, fol. 62r.: Escritura outorgada ante Bautista López o 17 de abril de 1665, pola que Ana Rodríguez do Monte, viuva do Capitán Sebastían de Vaamonde, veciño de Santa María de Trobo, dota a súa filla Constanza Vázquez para se casar con Marcos García e Parga, veciño da parroquia de Mourence, ofrecéndolle 500 ducados en bens e diñeiro.

14 V. Escritura outorgada en Felmil o 2 de marzo de 1675 ante Juan Vázquez da Pena, pola que Antonio López de Vaamonde permuta con Bautista Maseda e Aguiar, dándolle a iste o dereito de percibir unha renda anual de vinteoito cuartais de centeo sobre a terceira parte do lugar da Ponte de Rába- 
- Isabel de Vaamonde, que casou con Juan Vázquez, veciño de Cazás, en Xermade. Foi dotada polos seus pais con 300 ducados e roupas, o 8 de agosto de $1606^{15}$.

- Catalina de Vaamonde, que casou con Pedro Tenreiro de Lago, veciño de Felmil, dono da Casa Torre do Montecelo ${ }^{16}$. Foi dotada polos seus pais o 9 de xunio do 1616 con 250 ducados en pan de renda de bens en Pígara ${ }^{17}$, facéndose efectiva a dita dote o 21 novembro do 1621, intre no que Pedro Tenreiro de Lago deu carta de pago a favor do seu sogro dos 250 ducados prometidos ${ }^{18}$.

- Gregorio Vázquez e Parga, que marchou ó reino de Sevilla.

- E Gaspar de Vaamonde, que tamén marchou de Galiza para o reino do Perú.

\section{O PATRIMONIO DE GASPAR LÓPEZ DE VAAMONDE}

Coma se deduce pola información contida no Apéndice Documental, Gaspar López non se conformou cos bens herdados ó redor da Casa Torre de Trobo ${ }^{19}$, sinón que os incrementaría mercando novas herdades, sobor de todo nista parroquia de Trobo, e nas limítrofes de Santiago de Felmil e San Xiao de Gaibor, e en menor medida, en San Pedro de Pígara e San Martiño de Pacios.

Ademáis débese suliñar que o 29 de xaneiro do 1611, o cabido lucense outórgalle a el e a súa muller a metade do couto de Romariz (San Salvador de Damil, Begonte, Lugo), por pago de oito fanegas e media de centeno de renda anual ${ }^{20}$, deducíndose que pasaría a sere cotitular dos dereitos xurisdiccionais inherintes ó señorío do couto.

Todo isto denota que Gaspar López de Vaamonde administraba ben as súas rentas (v. figura 1) e que gozaba de boas relacións: o primeiro dedúcese porque invertía diñeiro na compra de terras xeneradoras de novos ingresos, trocaba outras para

\footnotetext{
de, dóus labradíos nas agras de Carral e da Igrexa, e outra na de Cabanelas, todas sitas en San Vicenzo de Rábade, e dando o Bautista Maseda ó López de Vaamonde a casa e lugar de Mourentán. LUGO, Archivo de Gaibor, leg. 8, n. 65.

${ }^{15}$ V. doc. n. ${ }^{\circ} 57$ do AD, outorgado en Ínsua.

${ }^{16}$ V. doc. n. ${ }^{\circ} 60$ do AD. Noticias xenealóxicas diste matrimonio poden verse en Pablo S. OTERo Piñeyro Maseda, Miguel Romaní Martínez e Xosé Antón García GonZález-Ledo, «Un hidalgo chairego del S. XVII: aspectos sociológicos con base documental», Estudios Mindonienses, 21 (2005), páxs. 709-741.

${ }^{17}$ V. doc. n. ${ }^{\circ} 60$ do $\mathrm{AD}$.

${ }^{18}$ V. doc. n. ${ }^{\circ} 61$ do AD, outorgado en Trobo.

${ }^{19}$ Tamén percisbía parte do beneficio patrimonial sen cura da parroquia de Trobo: v. doc. $n .^{\circ} 1$ do AD.

${ }^{20}$ V. doc. n. ${ }^{\circ} 59$ do AD, outorgado en Lugo.
} 
mellorar as que xa posuía, arrendaba logares ${ }^{21}$, mercaba rendas ${ }^{22} \ldots$ e incruso prestaba diñeiro a algún dos seus conveciños ${ }^{23}$. O segundo, intúiese ó outorgar escrituras, por exempro, con Juana Díaz de Saavedra, viuva de Pedro López de Rábade, señor do couto de Gaibor ${ }^{24}$ (v. figuras 2 e 3), ou con outra de merca dun lugar na Igrexa de Trobo, que estaba pensionado con media fanega de pan e unha galiña a pagar a don Fernando das Seixas, señor dos coutos de Felmil e Damil, da fortaleza de San Paio de Narla ${ }^{25}$.

É, en suma, un bo exempro de fidalgo que aínda rexe directamentes seu patrimonio, contando para seu servizo cos criados nescesarios ${ }^{26}$.

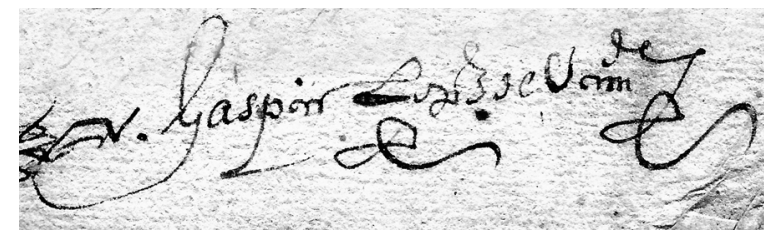

Figura 1. Sinatura de Gaspar López de Vaamonde

LUGO, Archivo de Gaibor, leg. 7, n. ${ }^{\circ} 80$.

\section{OS PROBREMAS SUCESORIOS DE GASPAR LÓPEZ DE VAAMONDE}

Coma se ten dito, moitos dos bens de Gaspar recaíron no seu fillo, o Capitán Sebastián de Vaamonde e Parga, que suponse foi mellorado en terzo e quinto. Antre elos encontraríase a Casa Torre de Trobo, que no S. XVIII xuntóuse coa do Souto, o cal propiciará en certa medida o progresivo abandono e demolición da devandita torre a comenzos do $\mathrm{S}$. $\mathrm{XX}^{27}$.

${ }^{21}$ V. doc. n. ${ }^{\circ} 44$ do AD, outorgado en San Martiño de Pazos.

${ }^{22}$ V. doc. n. ${ }^{\circ} 62$ do AD, outorgado en Trobo.

${ }^{23}$ V. doc. n. ${ }^{\circ} 11$ do AD, outorgado en San Martiño de Pino.

${ }^{24}$ V. doc. n. ${ }^{\circ} 53$ do AD, outorgado en Gaibor. Juana Díaz de Saavedra foi a terceira muller de Pedro López de Rábade Sanmartín, señor de Gaibor; tiveron por fillo a Pedro López de Rábade e Saavedra, señor de Gaibor, que casou con dona Catalina Teijeiro, sendo ambos os promotores da Casa Palacio de Gaibor en 1616, segundo consta nas labras heráldicas que se pubrican. V. José María CoIRA SANJURJo, «La Casa-Palacio de Gaibor», Boletín de la Comisión provincial de Monumentos Históricos y Artísticos de Lugo, 7, $\mathrm{n}^{\text {os }}$. 61-62 (1964), 285-289.

${ }^{25}$ V. doc. n. ${ }^{\circ} 55$ do AD, outorgado en Trobo.

${ }^{26}$ No doc. n. ${ }^{\circ} 64$ do AD, outorgado en Trobo en marzo de 1630, interveñen coma testemuñas «...Pedro Amigo y Antonio Albariño, hixo, e criados del dicho Gaspar López...».

${ }^{27}$ Ó Capitán Sebastián de Vaamonde o sucedería seu fillo primoxénito, o tamén Capitán don Antonio de Vaamonde e Parga, que casou con dona Francisca de Parga e Gayoso; a eles sucedeulle don José 
Mais, si ben paresce probado que o Capitán Sebastián de Vaamonde e Parga herdou do seu pai Gaspar a Casa Torre de Trobo, noustante, hai unha aparente contradicción: o 30 de xuño do $1653^{28}$, un sobriño de Sebastián chamado Antonio López de Vaamonde -fillo da irmá de Sebastián, Catalina de Vaamonde, e de Pedro Tenreiro de Lago- outorga en Lugo unha escritura ante o escribán Domingo Maseda, na que se recoñece ter rescibido un préstamo de 150 ducados do coengo lucense don Gabriel Mejía ${ }^{29}$. Para maior seguridade da devolución do préstamo, noméanse ademáis unhos fiadores, que o serán Juan Vázquez da Pena, escribán ${ }^{30}$, e Pedro Tenreiro de Lago, pai de Antonio López de Vaamonde, que

«... para mayor seguridad de dicha obligación que hacen de dichas sus personas y vienes, el dicho Pedro Tenreiro de Lago, además de los vienes ypotecados en esta escritura, ypotecaba e ypotecó el lugar de Trobo, con su torre y cassas, y todo lo más a él anexo y perteneciente, sito en la feligresía de Santa María de Trobo, en que al presente vibe Bartholomé Villete, por que le pagan de rrenta doçe fanegas de pan y seis capones...».

\footnotetext{
Antonio de Vaamonde e Parga, que do seu matrimonio con dona Elena Pardo Ribadeneira tivo a dona Mariana de Vaamonde Ribadeneira, que casaría con don Juan Varela, dono da Casa do Souto, en Cerdeiras. V. unha xenealoxía máis precisa, pero con algúns erros, e outras noticias referidas á Casa Torre de Trobo en Manuel VÁzQuez Seijas, Fortalezas..., T. IV, páxs. 159-161.

${ }^{28}$ LUGO, Archivo de Gaibor, leg. 7, n. 106.

${ }^{29}$ Constitúiese por elo a favor do dito coengo un «censo redimible» (pensión) de sete ducados e medio anuais, hipotecando como garantía do pago diversas rendas que xeneran distintos bens raíces de propriedade do dito Antonio López. É dicir, Antonio solicitou un préstamo ó coengo Mejía de 150 ducados; ten que devolverllos nun prazo, con unhos intereses anuais de 7,5 ducados. Como garantía do cobro, Antonio López hipoteca as rendas que lle producen uns bens da súa propriedade, de xeito que si non chegase a pagar o préstamo, ou os seus intereses, o coengo percibirá as rendas de aqueles bens.

${ }^{30}$ Algunhas noticias xenealóxicas e documentais do escribán Juan Vázquez da Pena pódense ver en Pablo S. Otero Piñeyro Maseda, Miguel Romaní Martínez y Xosé Antón García GonzÁlezLEDO, «Un hidalgo chairego...», páxs. 709-741.
} 


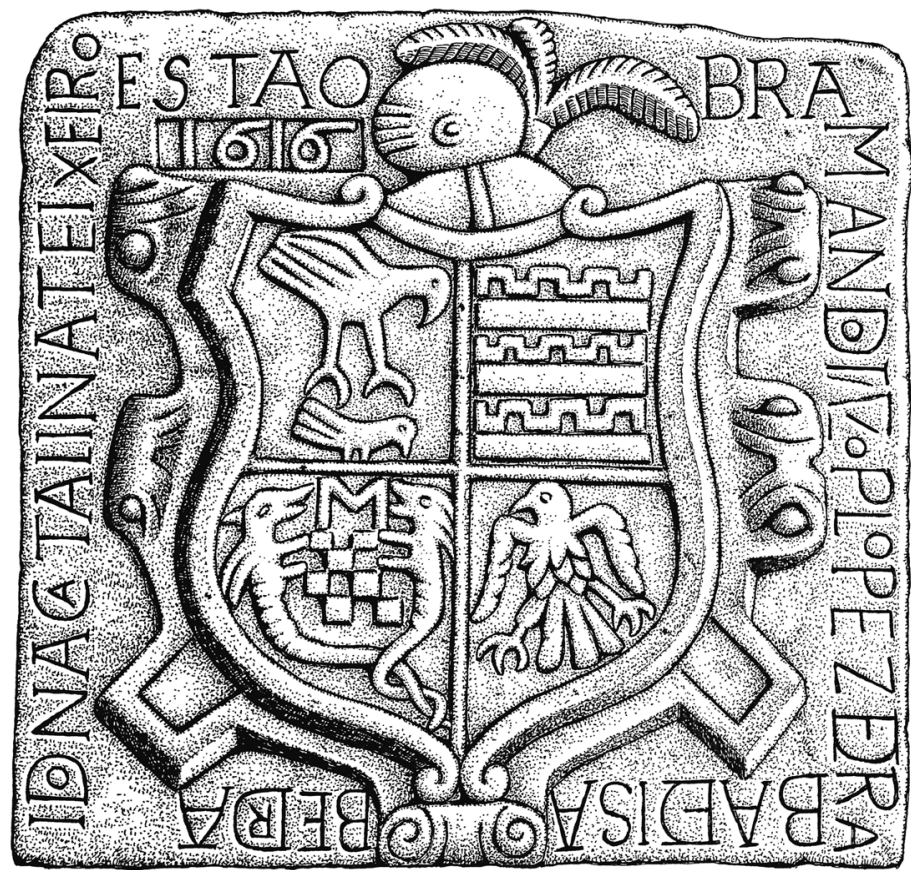

FEGIT XX (Q) MMIII.

Figura 2. Labra heráldica da dereita da fachada principal, mirando de fronte, da Casa Pazo de Gaibor, parroquia de San Xiao de Gaibor,

Begonte, Lugo.

Sobre cartela, un cuartelado en cruz, e timbrado de elmo con tres prumas. No primeiro, unha rapaz sobre unha pequena $a^{31} \mathrm{e}^{31}$; no segundo, tres faixas e tres xaqueles; no terceiro, un xaquelado sumado dunha «M» cunhas serpes cos rabos ensarillados, a maneira de tenantes; no cuarto, unha águia esplaiada. Todas elas corresponden ás linaxes de Saavedra, Vaamonde e Aguiar ou Pardo. Rodea ó conxunto a seguinte inscripción, en letras refundidas, e a data en relevo:

ESTA OBRA / MANDO [HACER] P(EDRO) LOPEZ DE RA/BADE I SABEDRA / I DONA CATALINA TEIXEIRO / 1616

${ }^{31}$ A interpretación de algúns autores de que é «una garza sobre un caldero» é errada. V. Antonio Benito Yebra de Ares, Pazos y señoríos de la provincia de Lugo, T. II, Servicio de Publicaciones, Diputación Provincial de Lugo, Salamanca, 1999, páx. 129. 


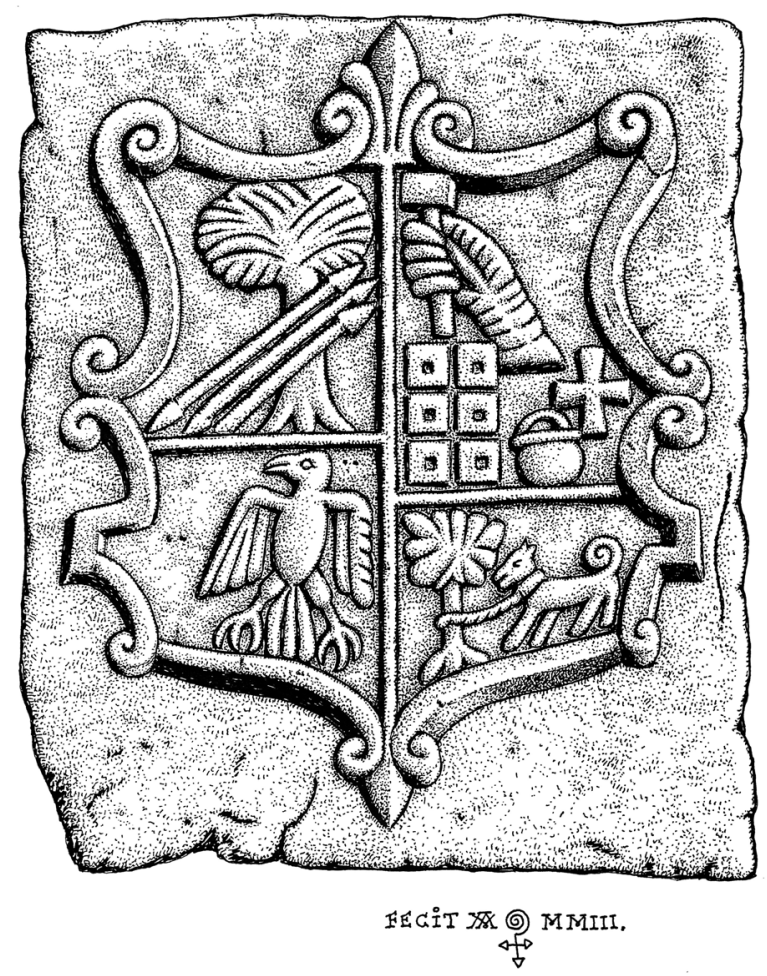

Figura 3. Labra heráldica da esquerda da fachada principal, mirando de fronte, da Casa Pazo de Gaibor, parroquia de San Xiao de Gaibor, Begonte, Lugo.

Nun cuartelado irregular, no primero, tres lanzas brochantes sobre unha árbore; no segundo, un brazo armado cun martelo, seis dados e un caldeiro cunha cruz; no terceiro, un águia espraiada; e no cuarto, un can amarrado a unha queiruga ou carballo. Representan as armas dos Lanzós ${ }^{32}$, Somoza e Neira, Aguiar e Quiroga.

No texto antecedente está a contradicción que se anticipaba liñas atrás, pois sabendo que a Casa Torre de Trobo pertenesce ó Capitán Sebastián de Vaamonde e Parga, non se exprica agora como o seu cuñado figura hipotecando a casa que pertenesce ó mentado Capitán. A falla doutras expricacións, e dado que os bens dei-

$32 \mathrm{O}$ mentado autor volve a cometer un erro na interpretación das armerías: dí que son as armas dos Valladares. Íd. ib. páx. 129. 
xados por Gaspar e súa muller Constanza comezaron a se dividir alomenos dende o ano $1633^{33}$, pode supoñerse que o marido da súa irmá -Pedro Tenreiro de Lagotivese poderes para representar ó Capitán na súa ausenza: aspectos istos que escapan á lóxica contemporánea, sen dúbida porque non se coñecen os pormenores e mesenterio das estipulacións feitas no seu momento ${ }^{34}$.

\section{DISTINCIÓN SOCIAL}

O escudo de armas, na súa calidade de signo de propriedade, aparesce de forma visíbel e notoria nos sepulcros, o mesmo que noutros bens ou obxectos do seu dono: casas, capelas, retáboos... A heráldica non soio identifica ó individuo que repousa no xacigo ou a linaxe da que formou parte, sinón que ademais quere afirmar a súa pertenza a un estamento superior ${ }^{35}$.

A pesares de participar das preocupacións, usos, costumes e entorno rural campesiño, a preeminenza social do fidalgo Gaspar López de Vaamonde non se manifiesta sóio na súa capacidade de actuación económica; gozaba de recoñecimento social facendo gala da súa linaxe ostentando as armas da súa Casa Torre de Trobo, e, posteriormentes, as poñerá con fachenda na súa propria sepultura, xunto coa súa muller Constanza Vázquez de Parga.

Os seus diversos sucesores, Catalina de Vaamonde, da Casa Torre do Montecelo, Antonio López Tenreiro Vaamonde (ou López de Vaamonde), da Casa Grande dos Navás... por mentar os máis cercanos, seguirán utilizando os embremas heráldicos familiares. Outras xeneracións, xa no S. XVIII e establecidas no Pazo de Souto, continuarán na lembranza da linaxe, perdurando asín deica os nosos días.

$\mathrm{E}$, dado o interés que ofrecen istos aspectos, nas liñas que seguen estudaranse en detalle as manifestacións heráldicas e arquitectónicas correspondentes á liña de Gaspar López de Vaamonde.

${ }^{33}$ V. de novo o doc. n. ${ }^{\circ} 65$ do AD.

${ }^{34}$ Finalmentes, o 16 de marzo de 1655, en escritura outorgada ante o escribán Pedro de Castro, Antonio López de Vaamonde redimiría o debandito censo, pagando ó coengo Mejía os 150 ducados e as anualidades correspondentes, motivo polo que non houbo nengún tipo de traspaso de rentas ou bens a mans do coéngo lucense, o cal dende logo non se quedou cos bens da Casa Torre de Trobo nin coas súas rentas. V. LUGO, Archivo de Gaibor, leg. 7, n. 106.

${ }^{35}$ V. Xosé Antón García GonZÁlez-Ledo, «A orante de Vasco Taboada do Carrio (século XVII), Descubrindo Deza. Anuario de Estudios e Investigación, 7 (2005), páx. 16, n. 14. 


\section{A CASA TORRE DE TROBO}

A que foi vivienda habitual de Gaspar López de Vaamonde non chegou deica os nosos tempos; derrubada a comenzos do S. XX, cos seus restos e entullos, edificouse outra casa no mesmo lugar da Torre (v. figura 4). Trátase dun bo exempro de aproveitamento dos materiais dunha construcción máis antiga, bastante ben elaborada, utilizando pedras de cantería traballada nas xambas e lumieiras de portas e fiestras, e cachotes de pizarra. O teito vai a catro augas, con lousas de pizarra, e remátase no cumio con dous pináculos. No seu entorno conserva algunhas construccións anexas de menor calidade.

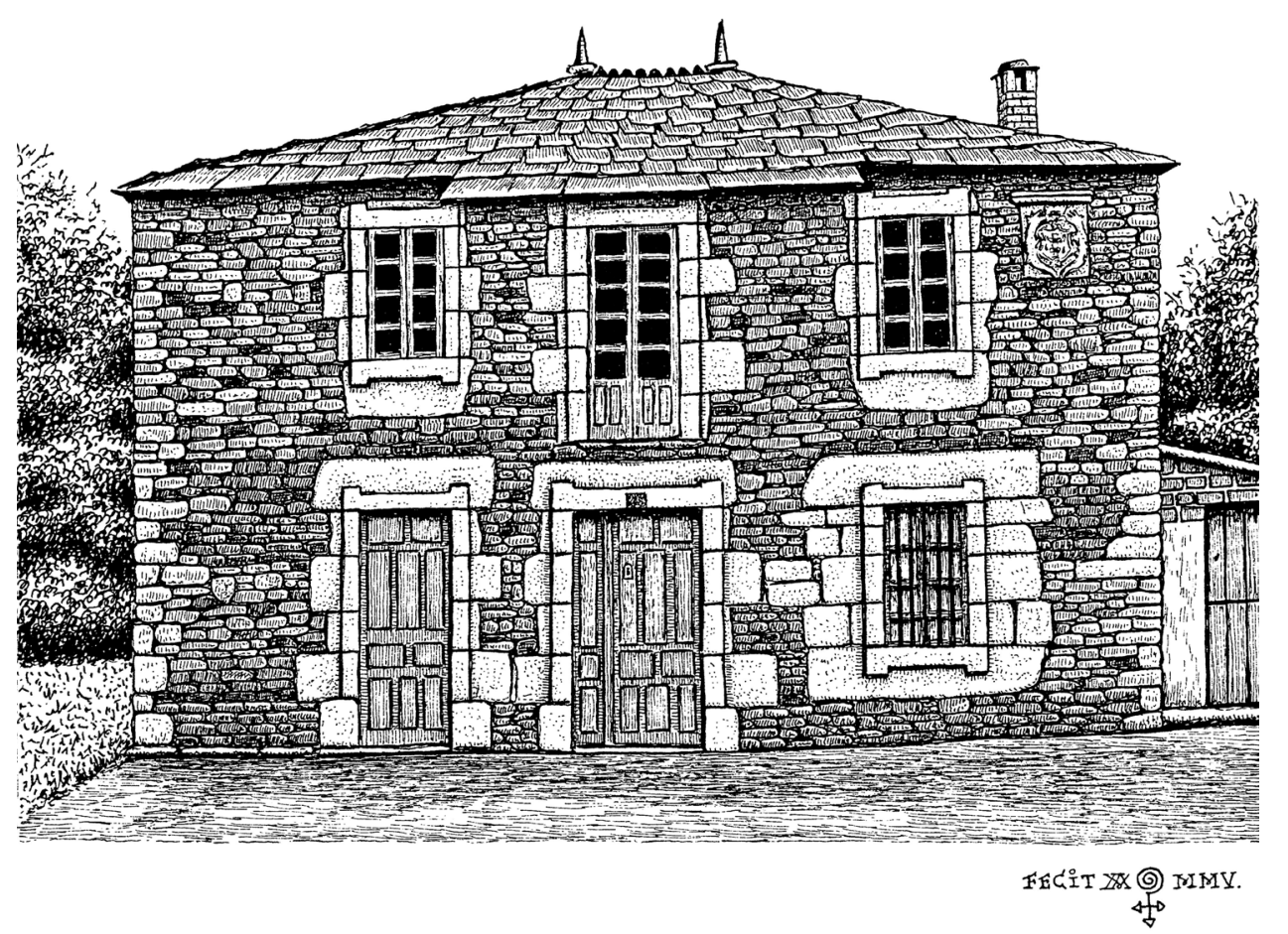

Figura 4. Casa edificada a comezos do S. XX cos restos da Casa Torre de Trobo. Lugar da Torre, parroquia de Santa María de Trobo, Begonte, Lugo

Reaproveitada da antiga Casa Torre, campa no lado esquerdo da fachada principal do novo edificio unha importante labra heráldica (v. figura 5). No seu campo ten unhos escaques con dúas troitas na diestra e na siniestra, e outra troita na punta, dentro dun escudo de forma irregular con escotaduras, timbrado dunha «M»-un 
pouco tosca- sumada dunha coroa, e dúas serpes ou lagartos alados a xeito de tenantes, representando ás armas dos Vaamonde.

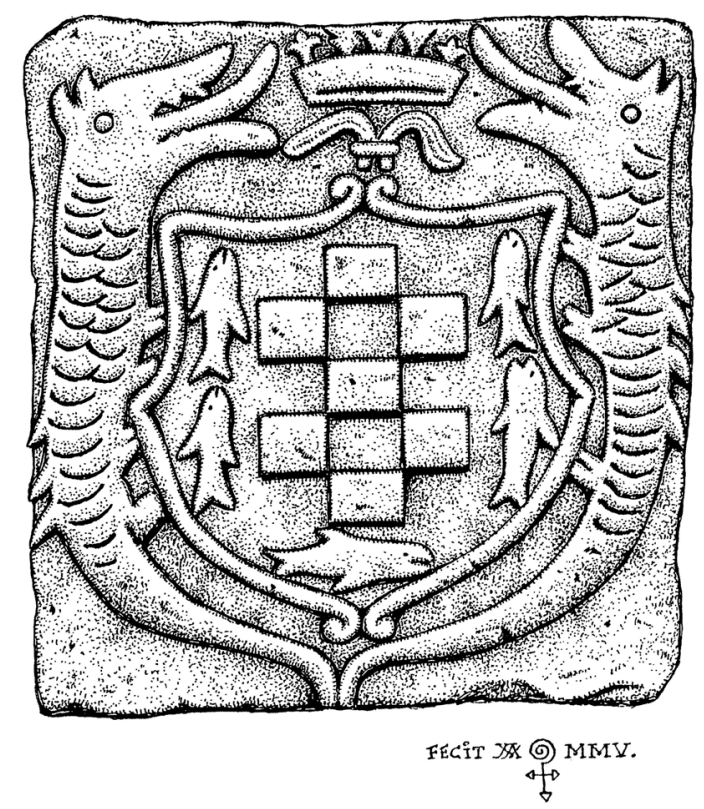

Figura 5. Labra heráldica da antiga Casa Torre de Trobo, hoxe na casa edificada cos restos daquela.

Lugar da Torre, parroquia de Santa María de Trobo, Begonte, Lugo.

\section{TAMPA SEPULCRAL DE GASPAR LÓPEZ DE VAAMONDE E SÚA DONA ${ }^{36}$}

Procedente da igrexa parroquial de Santa María de Trobo, atópase na actualidade na colección de heráldica do Museo Provincial de Lugo (v. figura 6). Foi donada por José María Coira Sanjurjo o 4 de decembro de 1971, e mide $162 \mathrm{~cm}$. de longo por $56 \mathrm{~cm}$. de ancho. Segundo Manuel Vázquez Seijas ${ }^{37}$, esta lauda estaba situada no chan da devandita igrexa parroquial á dereita do presbiterio, figurando

${ }^{36}$ Esta sepultura insírese no livro Escultura funeraria e heráldica no Museo Provincial de Lugo, do que son autores Xosé Antón García González-Ledo e Eduardo Pardo de Guevara y Valdés, de próxima aparición.

${ }^{37}$ Manuel VÁzquez SeIJAs, Fortalezas..., T. IV, páxs. 161. 
aínda no seu primitivo emplazamento ${ }^{38}$ no ano 1967. O seu estado de conservación é só regular, pois está rota en varios sitios, e fáltalle boa parte da inscripción. Ten labrado un escudo de forma irregular, medio partido e cortado, figurando no primeiro tres faixas; no segundo unha pomba ${ }^{39}$; e no terceiro un xaquelado rodeado de cinco peixes. Se corresponden ás armas dos Parga, Seixas e Vaamonde. Xa na bordura, coas letras en relevo, figura a seguinte lenda ${ }^{40}$ :

\section{S. DE GAS $[\ldots] /[\ldots] /[\ldots] /[\ldots]$ EZ DE PARGA SU MUJER}

Despois de manexar a documentación do Apéndice Documental, tirouse a concrusión que o texto sería o seguinte:

\section{S(epultura) DE GAS[PAR / LÓPEZ DE VAAMONDE I / DE CONSTANZA / VÁZQU]EZ DE PARGA SU MUJER}

O lugar onde se atopaba esta sepultura fora dotado anteriormente no ano 1535 por Manuel de Vaamonde ${ }^{41}$, devanceiro de Gaspar López de Vaamonde, xunto cun asento para muller e escano para home ${ }^{42}$. Gaspar aproveitou o lugar para facer unha nova sepultura, onde sería soterrado coa sua muller, Constanza Vázquez de Parga ${ }^{43}$, nos anos trinta do século XVII ${ }^{44}$.

\footnotetext{
${ }^{38}$ Aínda que cecais como esta igrexa foi refeita a finais do século XIX, posibelmentes xa a tiñan trocada de sitio.

${ }^{39}$ Cóidase que esta sexa unha forma abreviada das armas dos Seixas, que se da moito en algunhas partes da provincia de Lugo.

${ }^{40}$ Algúns autores que trataron antes ista peza, trabúcanse tanto na descripción das armerías como na lectura do epígrafe: v. Manuel VÁzQuez SeIJAs, Fortalezas..., T. IV, págs. 161, e Luis LóPEz Pombo no Boletín do Museo Provincial de Lugo, 11, vol. II (2004), páx. 189.

${ }^{41}$ Manuel VázQuez Seidas, Fortalezas..., T. IV, pág. 168.

42 V. un magnífico estudo sobre os dereitos nas igrexas como signo de prestixio en Ana Framiñán SANTAS, «Notas acerca de los derechos de los laicos en las iglesias parroquiales de Galicia (s. XIIIXV), Estudios Mindonienses, 21 (2005), páxs. 336-344.

${ }^{43}$ A autorización para a colocación dun sepulcro nun tempo, conlevaba o permiso para que sobor dil se escrebera o epitafio correspondente, de feito que ficara crara a testemuña da identidade do proprietario da sepultura. Algúns dos moimentos funerarios posúen inscripcións que, pola longura que pode acadar a súa superficie, constituien en ocasións un elemento fundamental no sartego. A riqueza de datos biográficos, históricos e ideolóxicos que se tiran do seu contido, os converten nunha fonte moi útil para o coñecemento do que coidaba sobre a vida e a morte. V. Xosé Antón GARCía GonZÁLEZ-LEDO, «A orante de Vasco...», páx. 16, n. 15.

${ }^{44}$ Como acontece en moitos casos nas dotacións de sepulturas, seguíronse soterrando nelas os seus descendentes; algún exempro en Manuel VÁzQuez SeIJAs, Fortalezas..., T. IV, páx. 161.
} 


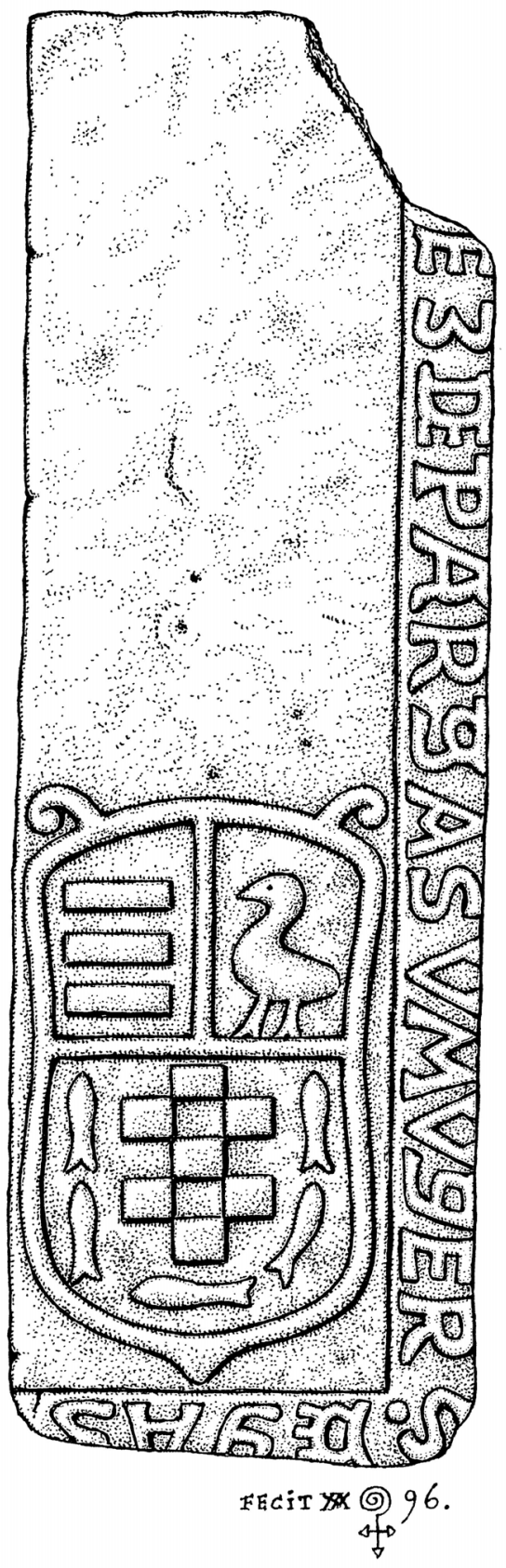

\begin{abstract}
Ana María Cuba Regueira ${ }^{45}$ suliña que no ano 1613 Gaspar López de Vaamonde fundara a capela de San Antonio, inserida na parroquial de Santa María de Trobo, de padroado da Casa Torre, con cárrega de dúas misas e do mantemento con óleo dunha lámpada, para que estivera decote acesa.
\end{abstract}

Figura 6. Tampa sepulcral de Gaspar López de Vaamonde e da súa muller Constanza Vázquez de Parga. Museo Provincial de Lugo, procedente da igrexa parroquial de Santa María de Trobo.

45 Ana María Cuba Regueira, El Condado de Vilalba en el Antiguo Régimen, [s.1.], Xunta de Galicia, Consellería de Educación e Ordenación Universitaria, 2005 (Serie Teses Doctorais), páx. 539. 


\section{CASA TORRE DO MONTECELO}

Ó mesmo que a Casa Torre de Trobo, foi demolida e, con seus restos, feita outra de nova construcción ${ }^{46}$, onde campa unha labra procedente de ela (v. figura 7). Presenta tres picos no xefe e escotaduras na diestra e na senestra, partida e medio cortada, figurando no primeiro un xaquelado sumado de dúas faixas e dúas troitas, alternadas; no segundo, igualmentes un xaquelado; e no terceiro unha «M» coroada de moi boa factura. Todos estes mobles aluden ó linaxe dos Gaioso e Vaamonde, dun xeito un pouco anárquico.

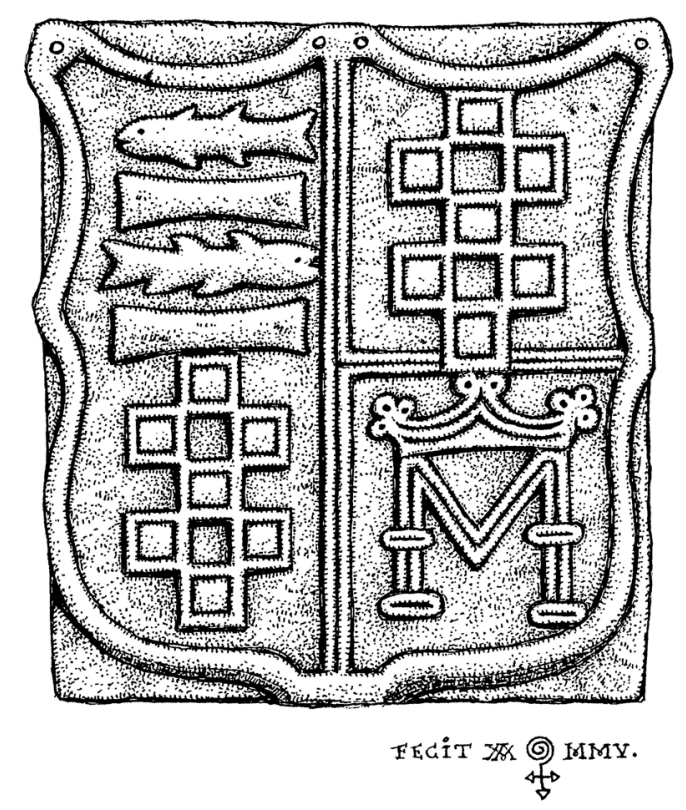

Figura 7. Pedra armeira da antiga Casa Torre do Montecelo, hoxe na casa edificada cos restos daquela, coñecida como «de Parguiña».

Lugar do Montecelo, parroquia de Santiago de Felmil, Begonte, Lugo.

\section{CASA GRANDE DOS NAVÁS}

Niste caso chegou ós nosos días un bo exempro de casa grande ou pousa, típica desta bisbarra (v. figura 8). Ten pranta en escadra composta de sobrado, baixo e faiado, con xambas e lumieiras en fiestras, bufardas, saeteiras e portas de ben labra-

46 V. debuxo da nova construcción en Pablo S. Otero Piñeyro Maseda, Miguel Romaní MartíNEZ y Xosé Antón GARCía GonZÁLEZ-LEDO, «Un hidalgo chairego...», páx. 711. 
da cantería, e o resto da obra de cachotes. O tellado é a catro augas, cuberto de lousas de pizarra, con pináculos e outros elementos decorativos. No seu entorno ten construccións anexas, como o pozo, alpendres ou subieiras, pombal, e outra interesante construcción chamada Casa do Forno. Todo o conxunto atópase rodeado de soutos e carballeiras, e outra vexetación autóctona. Ista construcción na actualidade atópase en proceso de rehabilitación polos seus propritarios, descendentes dos fundadores dela, no que se tentará conservar todos os elementos antigos que se poidan recuperar.

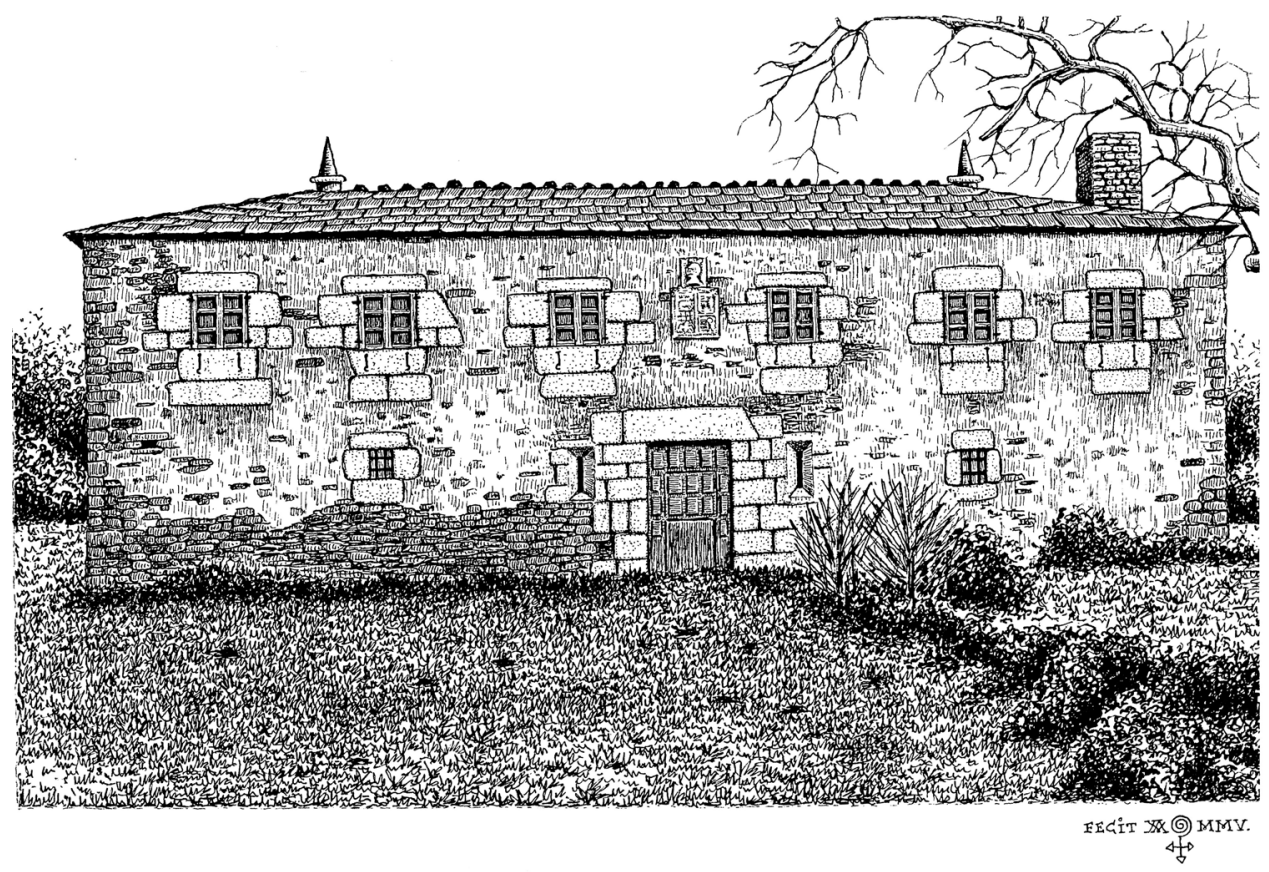

Figura 8. Casa Grande dos Navás.

Lugar dos Navás, parroquia de Santa María de Trobo, Begonte, Lugo. 
Na súa fachada principal, que mira cara o Sul, enriba da porta e antre dúas fiestras, campa unha fermosa labra de forma rectangular, partida e medio cortada, e noutra pedra máis pequena, facendo de timbre, un ben traballado e adestrado elmo (v. figura 9). No seu primeiro cuartel un tenreiro pasante e unhos escaques sumados a unha águia espraiada; no segundo unha «M» coroada rodeada de sete troitas; e no terceiro, catro faixas e unha árbore. Todo o conxunto corresponde ás armas dos Tenreiro ${ }^{47}$, Vaamonde, Aguiar e Parga. A árbore e o tenreiro tiñan de estar nun mesmo cuartel, e igualmentes o xaquelado coas troitas, para unha correcta e mellor distribución heráldica. Rodea o conxunto, en letras refundidas, a seguinte lenda:

\section{ESTA CASA HIZO AN/TONIO LÓPEZ T(EN)R(EIR)O I V(AA)M(ON)DE / I XOSEPA DE XINZO / MASEDA AGUIAR S(U) M(UJER). AN/O DE 1677}

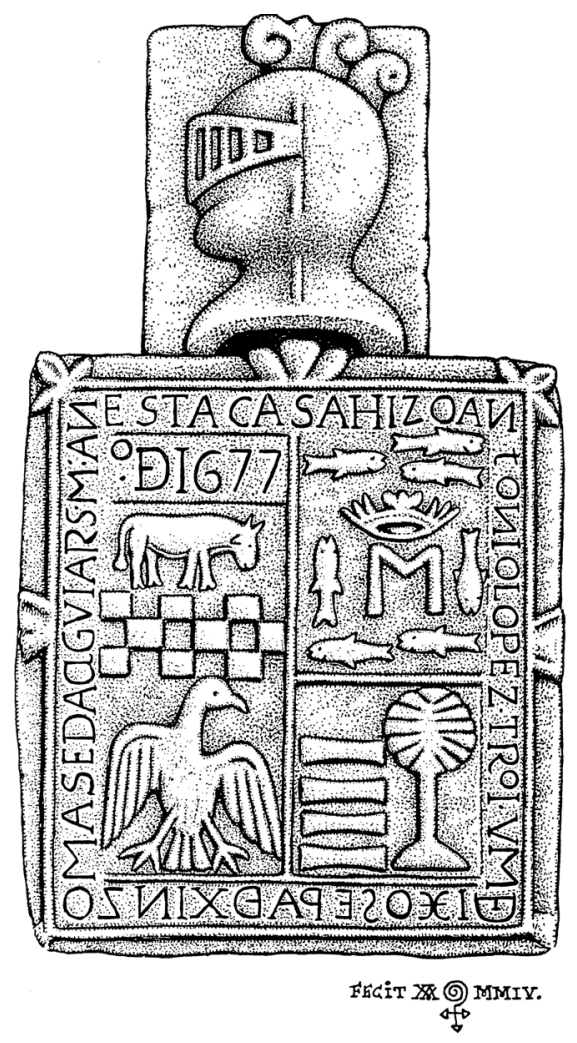

Figura 9. Pedra armeira da Casa Grande dos Navás.

Lugar dos Navás, parroquia de Santa María de Trobo, Begonte, Lugo.

${ }^{47}$ Para máis datos sobre esta linaxe v. José Enrique Ribadulla Porta e Xosé Antón García GonZÁLEZ-LEDO, «Heráldica do antigo coto de Leiro, Santa María do Castro-Miño-A Cruña», Brigantium, 2 (1981), páx. 223-245. Tamén en Xosé Antón García González-Ledo, Heráldica de Abegondo, A Coruña, [s.n.], 1994, páxs. 186-188. 


\section{PAZO DO SOUTO}

Sito na parroquia begontina de San Fiz de Cerdeiras, érguese ista construcción sobre pranta rectangular con dous adosados, feitos istes asín como a fachada en varias etapas, unha torre de base cadrada de tres andares, con fiestras e troneiras. Tamén destaca unha pequena capela cunha enxebre sineira ou campanario ( $v$. figura 10). Os tellados teñen cuberta de lousas de pizarra a catro augas e remátanse con pináculos. A vivenda componse de baixo, sobrado e faiado. Na fachada principal, hai unha fermosa pedra armeira, unha ampla porta e catro fiestras con montantes, bufardas, e troneiras, e outra porta máis pequena murada. As lumieiras, xambas, e esquinais son de granito, e o resto da obra de mampostería de pizarra. A parte traseira, ten unha longa solaina cuberta que mira ó xardín, co crásico pombal e longos e vedraños alcipreses a máis de árbores autóctonos, tamén de considerabel antiguedade. Todo o conxunto está rodeado dun outo muro con portalón, que pecha alprendes, pendellos, cabaleirizas, cortes e vivenda dos caseiros ${ }^{48}$.

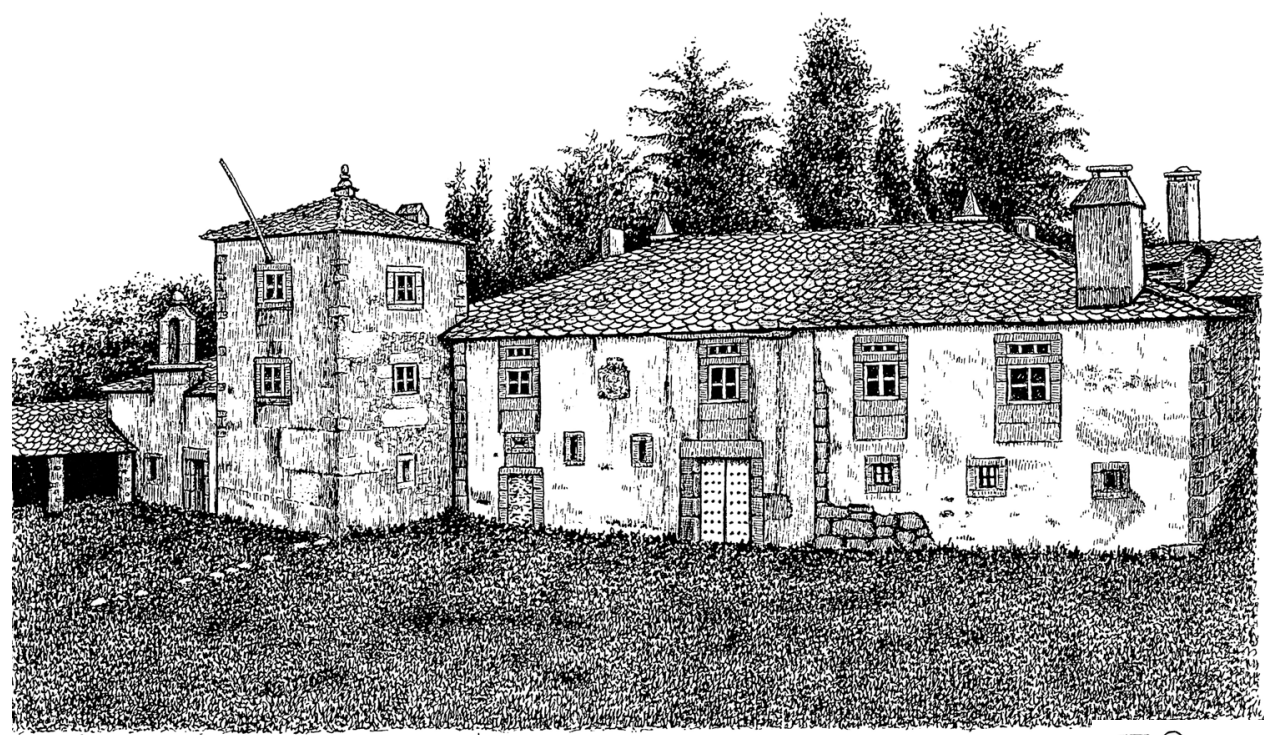

Figura 10. Pazo de Souto.

Lugar do Souto, parroquia de San Fiz de Cerdeiras, Begonte, Lugo.

ZXX (9) MMII. $\leftrightarrow$

${ }^{48}$ Segundo José María Coira Sanjurjo, nun manuscrito inédito titulado «Apuntes históricos sobre el Ayuntamiento de Begonte» que obra no seu arquivo sito no Museo Provincial de Lugo, referíndose ó Pazo do Souto, na páx. 46, dí que «no padrón de Calleita do ano 1702 figuraba coma nobre don Juan Varela Vaamonde, de Cerdeiras; no 1737 don José Antonio Varela das Seixas Saavedra Ribadeneira; no 1766, don Pedro Varela Vaamonde; no 1776 don Juan Varela Vaamonde...». 
A devandita pedra armeira (v. figura 11), é de forma redonda e cuartelada en cruz, e na súa bordura ten unha cadea de grandes elos cun candado na punta. No primeiro cuartel un águia pousada; no segundo unhas varas; no terceiro catro pombas, e no cuarto tres troitas gaiadas. Acolada, un águia bicéfala ${ }^{49}$, que sostén coas suas garras a embremática. Ó timbre, unha coroa, e toda a labra está decorada nas súas esquinas con motivos florais moi ben traballados.

Todo o conxunto, dun xeito anárquico, correponde ás linaxes dos Pardo ou Aguiar; Varela -varas e cadena-; Seixas e Gaioso ${ }^{50}$. Os cuarteis inferiores, arredados cunha cruz, que ben pode aludir dunha forma incompreta ós Ribadeneira, pois fáltanlle as crásicas vieiras.

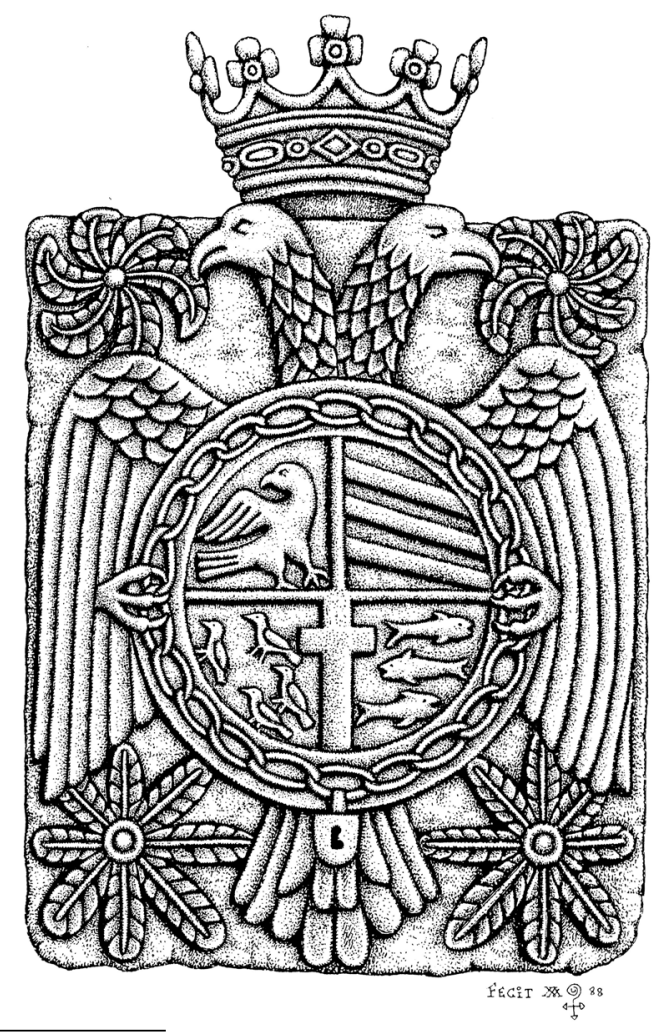

Figura 11. Pedra armeira do Pazo do Souto.

Lugar de Souto, parroquia de San Fiz de Cerdeiras, Begonte, Lugo.

${ }^{49}$ Recentementes algúns autores chámanlle "águila doble", o que é unga forma desaxeitada de describir a figura. V.

${ }^{50}$ As troitas da linaxe dos Gaioso fáltanlle as faixas, aínda que en moitas representacións máis antigas tampouco aparescen. Un bó exemplo témolo nos sartegos do século XV da capela do Pilar ou dos Reises, da Catedral de Lugo, que corresponden ó arcediano de Dozón don Gómez García de Gaioso, e a un seu parente sen identificar. V. Pablo S. Otero Piñeyro MASEdA, La Catedral de Lugo. Guía histórico-artística, Lugo, Diputación Provincial, 2005, páx. 35. 
Todo o dito demostra que aínda que se vai perdendo co paso do tempo a composición e sinxeleza das primitivas armerías, non ocorre o mesmo coa exhibición dos embremas pertenescentes ó linaxe. Asín pois, os descendentes de Gaspar López de Vaamonde non esquenceron a súa pertenza a tal estirpe, e por tanto deixaron numerosas testemuñas artísticas dela ás xeneracións futuras.

\section{Árbore xenealóxica de Gaspar López de Vaamonde ${ }^{51}$}

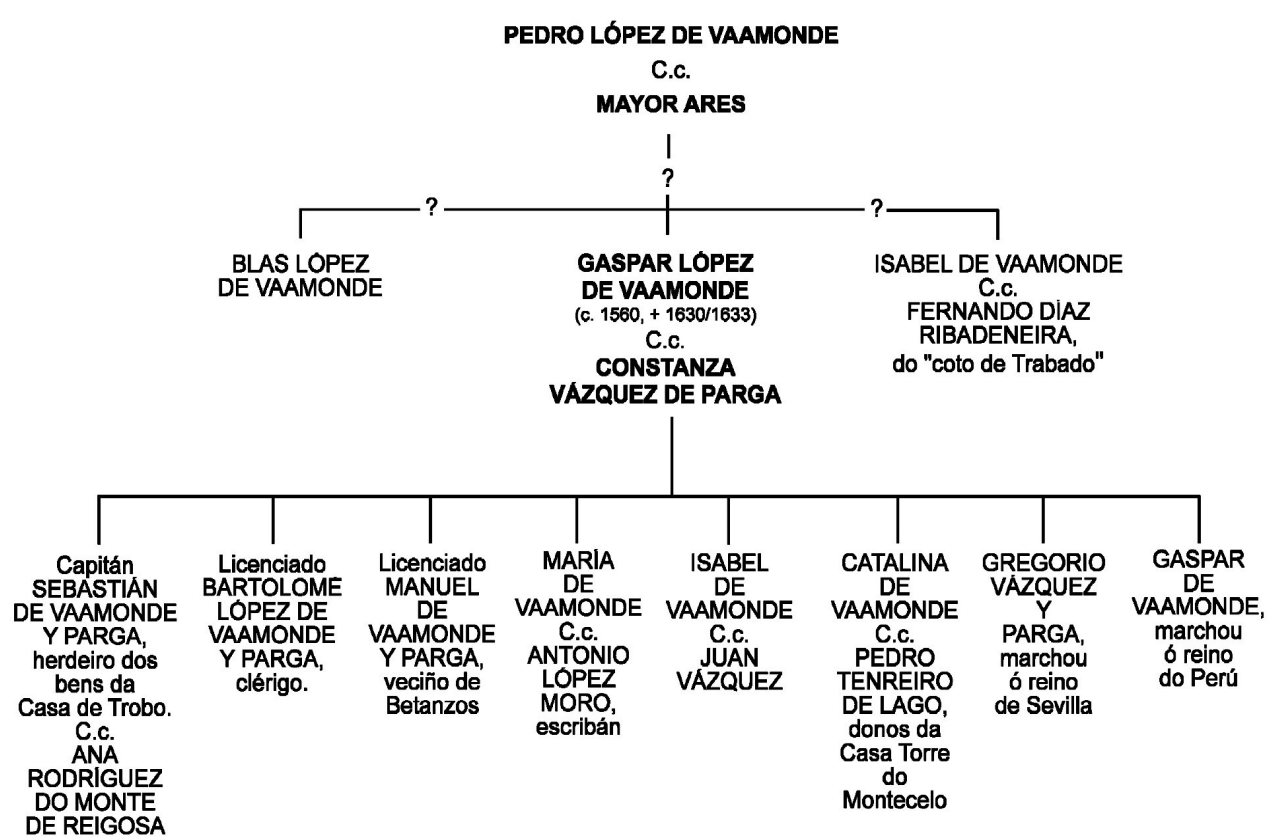

${ }^{51}$ Composición da árbore, xentileza do xenealoxista César Gómez Buxán. 


\section{APÉNDICE DOCUMENTAL}

\section{Criterios de edición}

- As indicacións referentes ó texto, e non presente nil, escrébense en letra cursiva antre paréntesis (cursiva).

- As frases ou verbas escritas sobre a liña antre renglóns, escríbense antre barras oblicuas $\backslash /$.

- As grafías aberrantes ou destacábeles sinálanse cun (sic).

- Os caracteres non presentes no texto, pero indispensábeles para seu senso, escríbense antre ángulos $<>$.

\section{Nota arquivística}

A maior parte dos documentos proceden do «Índice de Escrituras del Archivo de Souto», que contén os regestos da documentación que se custodiaba no pazo do Souto. Iste pazo, como ben se explicou, uniuse á liña sucesoria da Casa Torre de Trobo e nil concentrouse toda a documentación procente dila. A mediados do século XIX o pazo foi asaltado por unha gavilla de bandoleiros, espallándose e destruíndose gran parte da súa valiosísima e interesante documentación, da que en ocasións soio se conservan os regestos contidos no «Índice» ${ }^{52}$. Por elo, transcríbense istes regestos, respetado a súa ortografía e redacción, adaptándoos despois ás fichas catalográficas ó uso nas coleccións documentais. Sóio os documentos procedentes do «Archivo de Gaibor», que se conservan na actualidade do fondo documental procedente da Casa Grande dos Navás, se regestaron dun xeito habitual, escritos en letra cursiva e non en redonda.

\section{1}

1568, setembro, 14. Saavedra.

En Saabedra, a 14 septiembre 1568, a fe de don Andrés López de Rávade. Juan da Pena, de Carral, vendió a Pedro López de Bamonde el quiñón del veneficio patrimonial sin cura que a su madre pertenecía en el veneficio de Santa María de Trobo, que llebaba el Gaspar ${ }^{53}$, en renta anual de 6 celimines centeno en 77 reales de plata.

CERDEIRAS, Archivo del Pazo de Souto, Índice de Escrituras del Archivo de Souto, n. ${ }^{\circ}$ 1036, extr.

52 Os autores queren manifestar unha vegada máis a axuda e facilidades prestadas por don Antonio Fernández-Albalat para a consulta do «Índice de Escrituras del Archivo de Souto», asín coma as precisións suxeridas polo Prof. Miguel Romaní Martínez.

${ }^{53}$ Interprétase que, si ben o Índice dí «Gaspar», debería dicer «Pedro». 
1582, febreiro, 29. Trobo.

En Trobo, a 29 febrero de 1582, ante Gregorio Vázquez de Parga. Pedro da Cerdeira, vecino de Felmil, vendió a Gaspar López Baamonde y su muger una heredad de 5 celemines en sembradura de centeno, y otra de 3 celemines, sitas en Santiago de Felmil, en 82 reales y medio.

CERDEIRAS, Archivo del Pazo de Souto, Índice de Escrituras del Archivo de Souto, n. ${ }^{\circ} 756$, extr.

1584, xaneiro, 4. Gaibor.

En Gaybor, a 12 de marzo, 1584, ante Pedro do Mato. Basco de Rebordans y otros vecinos de dicho coto, en nombre de todos ellos dieron a Gaspar de Baamonde una leira en el Agra de Fabás por encargarse de cerrarla todos los años.

CERDEIRAS, Archivo del Pazo de Souto, Índice de Escrituras del Archivo de Souto, n. ${ }^{\circ} 633$, extr.

\section{4}

1586, maio, 10. Vilalba.

En Villalba, a 10 marzo de 1586. Ante Basco Fernández, escribano de la misma villa. Gonzalo Méndez, vecino de Trobo, cedió de la oposición que había hecho contra Gaspar López de Baamonde, de la posesión que había tomado del prado de Paxe, que adquiriera dicho Gaspar de Bartolomé de Parga, y se apartó del pleito que tenían sobre ello.

CERDEIRAS, Archivo del Pazo de Souto, Índice de Escrituras del Archivo de Souto, n. ${ }^{\circ}$ 760, extr.

1587, setembro, 21. Trobo.

En Trobo, a 21 septiembre, 1587, ante Gregorio Vázquez de Parga. Fernando de Martul vendió al Gaspar una leyra de heredad, sembradura 3 fanegas.

CERDEIRAS, Archivo del Pazo de Souto, Índice de Escrituras del Archivo de Souto, n. ${ }^{\circ} 1280$, extr. 
1587, decembro, 8. Felmil.

En Felmil, a 8 diciembre, 1587, ante don Domingo Fernández, escribano de ídem (Felmil). Álvaro do Regueiro, de dicho Felmil, vendió a Gaspar de Baamonde, vecino de Trobo, la mitad del prado de la Trémoga de Fabás y fuente que allí está en 7 ducados.

CERDEIRAS, Archivo del Pazo de Souto, Índice de Escrituras del Archivo de Souto, n. ${ }^{\circ} 771$, extr.

1588, xaneiro, 26. Trobo.

En Trobo, a 26 enero 1588, ante don Gregorio Vázquez de Parga. Bartolomé de Parga vendió a Gaspar López Baamonde una pieza de prado en los de Paxe. Siguen diligencias de posesión.

CERDEIRAS, Archivo del Pazo de Souto, Índice de Escrituras del Archivo de Souto, n. ${ }^{\circ}$ 689, extr.

1588, abril, 2. Felmil.

En Felmil, a 2 abril, 1588, ante don Domingo Fernández, de dicha feligresía. Pedro Bellete, de ídem, vendió a Gaspar López Baamonde dos piezas en el agra do Barreiro, sembradura 6 celemines, en 64 reales de plata.

CERDEIRAS, Archivo del Pazo de Souto, Índice de Escrituras del Archivo de Souto, n. ${ }^{\circ} 655$, extr.

1588, xuño, 10. Trobo.

En Trobo, a 10 de junio, 1588, ante don Gregorio Vázquez de Parga. Pedro do Barreiro y su mujer, de la aldea de Martín, en Trobo, vendieron a Gaspar López Vaamonde dos leiros en el agra de Vechicán, en 24 reales.

CERDEIRAS, Archivo del Pazo de Souto, Índice de Escrituras del Archivo de Souto, n. ${ }^{\circ}$ 665, extr.

\section{0}

1590, xuño, 3. Vilalba.

En Villalba, a 3 junio 1590, ante don Basco Fernández. Francisco de Martul vendió a Gaspar López Baamonde la mitad del prado de Paxe, en 62 reales.

CERDEIRAS, Archivo del Pazo de Souto, Índice de Escrituras del Archivo de Souto, n. ${ }^{\circ}$ 687, extr. 
1592, xaneiro, 23. San Martiño de Pino.

En San Martín do Pino, a 23 enero, 1592. Pedro da Ynsoa se obligó a pagar a Gaspar López de Baamonde, vecino de Trobo, 42 reales que le debía por razón de empréstito. Es papel simple.

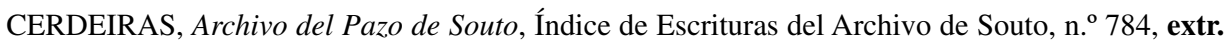

12

1592, maio, 3. Vilalba.

En Villalba, a 3 de mayo de 1592, ante Basco Fernández. Pedro de Galdo, vecino de Felmil, vendió a Gaspar López de Vaamonde, vecino de Trobo, una leira de heredad sita en el villar del Piñón Grande, en Felmil, sembradura 5 celemines, en 71 reales y medio.

CERDEIRAS, Archivo del Pazo de Souto, Índice de Escrituras del Archivo de Souto, n. ${ }^{\circ} 765$, extr.

1592, decembro, 16. Pino.

En Pino, a 16 diciembre 1592, ante don Pedro do Mato. El Alonso (Alonso Díaz) vendió al Gaspar un prado y veiga en los prados da Paxe, en 6 ducados y 6 reales. CERDEIRAS, Archivo del Pazo de Souto, Índice de Escrituras del Archivo de Souto, n. o 693, extr.

\section{4}

1593, marzo, 2. Trobo.

En Trobo, a 2 marzo, de 1593, ante Gregorio Vázquez de Parga, escribano de San Martín de Pazos. Antonio de Martul, de la dicha de Trobo, vendió con licencia de su curador Juan Rodríguez, vecino de Santiago de Yllán, a Gaspar López de Baamonde una leira de heredad sita en vilar de André, de Martín, en dicha feligresía, sembradura dos fanegas, en 82 reales y medio.

CERDEIRAS, Archivo del Pazo de Souto, Índice de Escrituras del Archivo de Souto, n. ${ }^{\circ} 781$, extr. 
1593, marzo, 28. Felmil.

En Felmil, a 28 marzo, 1593, ante don Domingo Fernández. Gaspar López Baamonde y Antonio da Granda, de dicha feligresía, trocaron unas leiras en las cortiñas do Burgo.

CERDEIRAS, Archivo del Pazo de Souto, Índice de Escrituras del Archivo de Souto, n. ${ }^{\circ}$ 649, extr.

1594, marzo, 9. Felmil.

En Felmil, a 9 marzo, 1594, ante don Domingo Fernández, de dicha feligresía. Domingo Fernández, de ídem, dio a Gaspar López Baamonde 3 leyros en el agra de Libor, por otras tres piezas en el Piñón.

CERDEIRAS, Archivo del Pazo de Souto, Índice de Escrituras del Archivo de Souto, n. ${ }^{\circ}$ 659, extr.

1594, abril, 11. Felmil.

En ídem (Felmil), a 11 de abril, 1594, ante ídem (don Domingo Fernández). Antonio de Martul, de Yllán, vendió a ídem (Gaspar López Baamonde) 3 piezas en el agra de Paxe, al sitio de Portobaltar, en 62 reales de plata.

CERDEIRAS, Archivo del Pazo de Souto, Índice de Escrituras del Archivo de Souto, n. ${ }^{\circ}$ 672, extr.

1595, xaneiro, 12. Pacios.

En Pacios, a 12 enero 1595, ante Vázquez de Parga. El Alonso Díaz vendió al Gaspar dos leyros, uno en el villar de Vichicán, y otro en las cortiñas da Canle, en 42 reales.

CERDEIRAS, Archivo del Pazo de Souto, Índice de Escrituras del Archivo de Souto, n. ${ }^{\circ}$ 691, extr.

\section{9}

1595, maio, 4. Couto de Seguín?

En el coto de Seguín?, a 4 mayo 1595, ante Alonso do Monte, escribano. Fernando Colmelo y María de Prado, su mujer, de Felmil, dieron a Gaspar López de Baamonde, vecino de Trobo, dos leiros de heredad sitos en los vilares del Piñón Grande; otro en el vilar de Libor, en 30 reales.

CERDEIRAS, Archivo del Pazo de Souto, Índice de Escrituras del Archivo de Souto, n. ${ }^{\circ} 763$, extr. 
1595, maio, 18. Gaioso.

En Gayoso, a 18 mayo, 1595, ante ídem (Gregorio Vázquez de Parga). Alonso Díaz vendió al Gaspar tres piezas en Paxe y otras partes, en 90 reales de plata. CERDEIRAS, Archivo del Pazo de Souto, Índice de Escrituras del Archivo de Souto, n. ${ }^{\circ}$ 692, extr.

\section{1}

1595, xuño, 15. Rábade.

En Rábade, a 15 junio, 1595, ante don Juan López, de Rábade. Alonso Díaz vendió a Gaspar López Baamonde la mitad de lugar en que vivía, y una leira arriva de dicho lugar, en 77 reales de plata, Ipagados/ en dinero y en una leira en el agra de Vechicán.

CERDEIRAS, Archivo del Pazo de Souto, Índice de Escrituras del Archivo de Souto, n. ${ }^{\circ} 663$, extr.

1596, maio, 18. Gaioso.

En Gayoso, a 18 mayo, 1596, ante don Gregorio Vázquez de Parga. Antonio Martul vendió al Gaspar dos leiras en el agra de Paxe, de una fanega, en 44 reales. CERDEIRAS, Archivo del Pazo de Souto, Índice de Escrituras del Archivo de Souto, n. ${ }^{\circ} 675$, extr.

1596, decembro, 26. Trobo.

En Trobo, a 26 diciembre 1596 años, ante don Pedro de Yllán, de Saabedra. Alonso Díaz de Trobo vendió al Gaspar una leira de 5 celemines en los campos de Fabás, en 36 reales.

CERDEIRAS, Archivo del Pazo de Souto, Índice de Escrituras del Archivo de Souto, n. ${ }^{\circ}$ 683, extr.

\section{4}

1597, febreiro, 12. Illán.

En Santiago de Yllán, a 12 febrero de 1597, ante don Gregorio Vázquez de Parga. Haciendo permuta Pedro Vázquez, de Trobo, dio al Gaspar un leiro en el agra da Paxe y sitio da Freiteira; y el Gaspar le dio otro en la misma agra y 14 reales.

CERDEIRAS, Archivo del Pazo de Souto, Índice de Escrituras del Archivo de Souto, n. ${ }^{\circ}$ 677, extr. 
1597, febreiro, 13. Trobo.

En Trobo, a 13 febrero, 1597, ante don Gregorio Vázquez de Parga, escribano. Alonso Díaz, vecino de dicha feligresía, vendió a Gaspar López de Baamonde 4 piezas de heredad sitas en la agra de Martiño?, donde dicen la Carballeira; en la agra de Fabás, donde dicen os Cerbelos; en la agra de Paxe; y en las cortiñas da Canle, en 57 reales.

CERDEIRAS, Archivo del Pazo de Souto, Índice de Escrituras del Archivo de Souto, n. ${ }^{\circ} 777$, extr.

\section{6}

1597, febreiro, 14. Felmil.

En Felmil, a 14 febrero, 1597, ante don Domingo Fernández, de dicha feligresía. Alonso da Lamela, de Trobo, vendió al Gaspar un leiro en el vilar de Vechicán, llamado del Rodo, en 31 reales de plata.

CERDEIRAS, Archivo del Pazo de Souto, Índice de Escrituras del Archivo de Souto, n. ${ }^{\circ}$ 671, extr.

1597, marzo, 9. Trobo.

En Trobo, a 9 marzo, 1597, ante don Pedro de Yllán, de Saabedra. Bartolomé da Lamela dio al Gaspar, haciendo permuta, una pieza donde dicen el Espino; y éste a aquél, una cortiña en el lugar de Martín, y 17 reales.

CERDEIRAS, Archivo del Pazo de Souto, Índice de Escrituras del Archivo de Souto, n. ${ }^{\circ}$ 669, extr.

1597, abril, 14. Felmil.

En Felmil, a 14 abril de 1597, ante don Domingo Fernández, escribano. Gaspar López de Baamonde, vecino de Trobo, y Pedro de Lamas, de dicho Felmil, hicieron cambio en el que dio el Gaspar López un pedazo de un leiro que estaba dentro del curro de Montecelo con más 7 reales en dinero; y el Pedro de Lamas un leiro de heredad en la agra de la fuente do Barrio.

CERDEIRAS, Archivo del Pazo de Souto, Índice de Escrituras del Archivo de Souto, n. ${ }^{\circ} 768$, extr. 


\section{9}

1597, abril, 14. Trobo.

En Trobo, a 14 abril 1597, ante Pedro de Yllán. Juan do Monte, de Felmil, y Juan da Cerdeira, de ídem, vendieron a Gaspar López de Baamonde, el 1. ${ }^{\circ}$, un leiro en el agra de Melite, de un celemín sembradura; y el 2. ${ }^{\circ}$ una leyra de 1 fanega sembradura en el agra de Costoya, y otro pedazo de terreno.

CERDEIRAS, Archivo del Pazo de Souto, Índice de Escrituras del Archivo de Souto, n. ${ }^{\circ} 1271$, extr.

1597, xuño, 1. Illán.

En Yllán, a 1. junio, 1597, ante Gregorio Vázquez de Parga. Antonio de Martul, de dicha feligresía, confirmó una venta que hiciera en su nombre Pedro Vázquez al Gaspar, de una cortiña en las da Calde, de media fanega $<$ de $>$ sembradura, en 66 reales de plata.

CERDEIRAS, Archivo del Pazo de Souto, Índice de Escrituras del Archivo de Souto, n. ${ }^{\circ}$ 673, extr.

\section{1}

1597, outubro, 13. Rábade.

En Rábade, a 13 octubre, 1597, ante don Juan López de Rábade. Alonso Díaz se apartó de pedir lesión por venta que hiciera al Gaspar de la mitad de la casa, era y huerta de Martín, y la cortiña da Pardineyra, por el aumento de precio de 44 reales y medio.

CERDEIRAS, Archivo del Pazo de Souto, Índice de Escrituras del Archivo de Souto, n. ${ }^{\circ}$ 690, extr.

1598, xaneiro, 4. Vilalba.

En Villalba, a 4 enero, 1598, ante don Basco Fernández. Francisco de Martul vendió al Gaspar un leiro en el agra de Paxe en 25 reales de plata.

CERDEIRAS, Archivo del Pazo de Souto, Índice de Escrituras del Archivo de Souto, n. ${ }^{\circ}$ 676, extr. 


\section{3}

1598, xaneiro, 17. Felmil.

En Felmil, a 17 de enero, 1598, ante don Domingo Fernández, de dicha feligresía. Diego Díaz Sanjurjo, de Pígara, vendió a Gaspar López Baamonde, toda la parte que compraron a Pedro de Santa Marina, de Pacios, en el lugar do Areal, en 84 reales de plata.

CERDEIRAS, Archivo del Pazo de Souto, Índice de Escrituras del Archivo de Souto, n. ${ }^{\circ} 639$, extr.

\section{4}

1598, xaneiro, 28. Felmil.

En ídem (Felmil), a 28 enero, 1598, ante ídem (don Domingo Fernández). Pedro Bello, de Villalba, vendió al Gaspar seis partes del lugar do Areal, en Pígara, y una 8. ${ }^{\text {a }}$ del molino, en 54 ducados.

CERDEIRAS, Archivo del Pazo de Souto, Índice de Escrituras del Archivo de Souto, n. ${ }^{\circ}$ 650, extr.

\section{5}

1598, febreiro, 24. Trobo.

En ídem (Trobo), a 24 febrero, 1598, ante ídem (don Pedro de Yllán). Haciendo trueque, Diego Romeu dio al Gaspar cinco piezas en el agra de Laxe; y éste a aquél, una en dicha agra.

CERDEIRAS, Archivo del Pazo de Souto, Índice de Escrituras del Archivo de Souto, n. ${ }^{\circ}$ 670, extr.

\section{6}

1598, marzo, 3. Trobo.

En Trobo, a 3 de marzo de 1598, ante ídem (Pedro de Yllán). María Fernández vendió a Gaspar López de Baamonde una pieza de cortiña sita en dicho Trobo, a donde dicen el rego de la Yglesia, sembradura media fenega, en 52 reales de plata. CERDEIRAS, Archivo del Pazo de Souto, Índice de Escrituras del Archivo de Souto, n. ${ }^{\circ} 775$, extr. 
1598, marzo, 24, Felmil.

En Felmil, a 24 marzo, 1598, ante ídem (don Domingo Fernández, escribano de Felmil). Gaspar de Baamonde y Juan Felpeto, vecinos de Trobo, hicieron cambio en el que dicho Gaspar dio una leira de heredad sembradura cinco celemines, sita al Piñón Grande; y el Juan Felpeto dio en recompensa otra leira de heredad sita en el agra de Fabás, donde dicen os Corbetos, sembradura seis celemines.

CERDEIRAS, Archivo del Pazo de Souto, Índice de Escrituras del Archivo de Souto, n. ${ }^{\circ} 772$, extr.

1598, abril, 13. Felmil.

En Felmil, a 13 abril 1598, ante don Domingo Fernández. Gregorio Marino, de Támboga (sic), vendió al Gaspar la mitad das leyras da Lamela, en Martín, y una cortiña a su largo y las tres cuartas partes de la casa vieja, en 18 ducados.

CERDEIRAS, Archivo del Pazo de Souto, Índice de Escrituras del Archivo de Souto, n. ${ }^{\circ}$ 694, extr.

1598, maio, 7. Gaibor.

En Gaibor, a 7 mayo, 1598, ante Domingo Fernández. El Bartolomé (Bartolomé da Lamela) vendió a Gaspar López Baamonde dos piezas en el tarreo de Sabecoy y Vilar de Vechicán en 30 reales.

CERDEIRAS, Archivo del Pazo de Souto, Índice de Escrituras del Archivo de Souto, n. ${ }^{\circ}$ 681, extr.

40

1598, maio, 12. Felmil.

En ídem (Felmil), a 12 mayo, 1598, ante ídem (don Domingo Fernández). Fernando de Martul, de Trobo, vendió a ídem (Gaspar López Baamonde) la mitad de la casa, lugar y bienes Su Ynfesta, y un pedazo de prado en los de Requeijo, en 27 ducados.

CERDEIRAS, Archivo del Pazo de Souto, Índice de Escrituras del Archivo de Souto, n. ${ }^{\circ}$ 647, extr. 
1598, maio, 14. Felmil.

En Felmil, a 14 mayo, 1598, ante ídem (Pedro de Yllán). El Pedro da Cerdeira y su mujer vendieron al Gaspar una leyra de 9 celemines en el agra da Seara.

CERDEIRAS, Archivo del Pazo de Souto, Índice de Escrituras del Archivo de Souto, n. ${ }^{\circ}$ 1272, extr.

1598, xullo, 7. Felmil.

En Felmil, a 7 julio, 1598, ante don Domingo Fernández. Elbira González, viuda, vendió al Gaspar una leyra de 2 celemines en el agra de Libor, en Felmil. CERDEIRAS, Archivo del Pazo de Souto, Índice de Escrituras del Archivo de Souto, n. ${ }^{\circ}$ 646, extr.

1598, xullo, 23. Trobo.

En Trobo, a 23 de julio de 1598, ante Pedro de Yllán. Marqueno? Do Campo e Ysabel Díaz, su mujer, vendieron a Gaspar López de Baamonde una leira de heredad sita en la agra de Fabás, donde dicen os Cerdelos, en dicho Trobo, sembradura 5 celemines en 40 reales.

CERDEIRAS, Archivo del Pazo de Souto, Índice de Escrituras del Archivo de Souto, n. ${ }^{\circ} 774$, extr.

\section{4}

1598, decembro, 2. San Martiño de Pazos.

En San Martín de Pazos, a 2 diciembre de 1598, ante Gregorio Vázquez de Parga, escribano. Gaspar López de Baamonde, vecino de la feligresía de Trobo, dio en arriendo a Pedro Alfonso, vecino de Pígara, el lugar de Areosa, sito en la feligresía de Pígara, y una heredad de 2 fanegas en sembradura en Vilar de Arriva, términos de la misma parroquia, y otros bienes, por espacio de 6 años, por la $3 .^{a}$ parte del trigo, mijo, horjo e nabos que hubiese en las cortiñas e heredades de dicho lugar, y el 5..$^{\circ}$ de todo lo que labrasen en los montes, y 4 capones y una cesta de pan de trigo por el día de Nabidad en cada un año, y tres ferrados de centeno.

CERDEIRAS, Archivo del Pazo de Souto, Índice de Escrituras del Archivo de Souto, n. ${ }^{\circ} 758$, extr. 
1598, decembro, 12. Gaibor.

En Gaibor, a 12 diciembre, 1598, ante don Domingo Fernández, de ídem (Gaibor). Basco de Rebordaos vendió a Gaspar López de Baamonde, de Trobo, una pieza junto el curro de Fabás, en 32 reales de plata.

CERDEIRAS, Archivo del Pazo de Souto, Índice de Escrituras del Archivo de Souto, n. ${ }^{\text {10 }}$ 1027, extr.

\section{6}

1599, febreiro, 29. Gaibor.

Gaibor, a 29 de febrero de 1599, ante don Domingo Fernández, de ídem (Gaibor). Juan Rodríguez de Tangoba (sic), vendió a Gaspar López de Baamonde un prado en los de Requeijo.

CERDEIRAS, Archivo del Pazo de Souto, Índice de Escrituras del Archivo de Souto, n. ${ }^{\text { }}$ 1057, extr.

\section{7}

1599, marzo, 15. Felmil.

En Felmil, a 15 marzo de 1599, ante don Domingo Fernández, de ídem (Felmil). Pedro Romeu y Alonso Romeu, hermanos, de dicha feligresía, y madre, por sí y una hija menor, vendieron a Gaspar López de Baamonde un prado sito en Ardefonse, en 7 ducados.

CERDEIRAS, Archivo del Pazo de Souto, Índice de Escrituras del Archivo de Souto, n. ${ }^{\circ}$ 1066, extr.

\section{8}

1599, marzo, 22. Trobo.

En Trobo, a 22 de marzo, 1599, ante don Pedro de Yllán, vecino de Saavedra. Antonio de Martul, de Yllán, vendió a Gaspar López de Vaamonde toda la herencia de sus padres Pedro de Martul y Maria Lamela, y de Basco de Martul, su abuelo, cuya herencia será de 26 celemines en 16 ducados.

CERDEIRAS, Archivo del Pazo de Souto, Índice de Escrituras del Archivo de Souto, n. ${ }^{\text {636, extr. }}$ 
1599, xullo, 4. Saavedra.

En Saavedra, a 4 julio, 1599, ante don Pedro de Yllán, de dicha feligresía. Fernando Díaz Rivadenyra, del coto de Trabado, y su mujer Ysabel de Vaamonde, y a nombre del hermano de ésta, Blas López de Baamonde, de quien era aquél curador, vendieron a Gaspar López de Vaamonde la mitad del celeiro de Lamela, del qual el comprador tenía la otra mitad y parte del formal contiguo, en precio de 9 ducados.

CERDEIRAS, Archivo del Pazo de Souto, Índice de Escrituras del Archivo de Souto, n. ${ }^{\circ} 743$, extr.

\section{0}

1599, xullo, 11. Felmil.

En Felmil, a 11 de julio, 1599, ante Domingo Fernández. Men Varela de Damil y su mujer vendieron a Gaspar López una fanega $<$ de $>$ sembradura en dos piezas en el Agra de Costoya, en 42 reales de plata.

CERDEIRAS, Archivo del Pazo de Souto, Índice de Escrituras del Archivo de Souto, n. ${ }^{\circ}$ 631, extr.

1599, decembro, 1. Felmil.

En Felmil, a 1. ${ }^{\circ}$ de diciembre de 1599, ante Pedro Vázquez de Aguiar, escribano de la fortaleza de Villajuán. Gaspar López de Baamonde y Martino do Campo, vecino de Trobo, han hecho trueque en el que Gaspar López dio la pieza de heredad sita donde dicen el tarreo de Cabeza, sembradura 2 ferrados; y el Martino dio dos piezas de heredad, una sita en la agra de Aldré, que llaman tarreo da Cruz, y llevará de sembradura una fanega de pan, y la otra en la agra de Paxe, donde dicen Freigeira, de un celemín en sembradura.

CERDEIRAS, Archivo del Pazo de Souto, Índice de Escrituras del Archivo de Souto, n. ${ }^{\circ} 778$, extr.

\section{2}

1601, decembro, 26. Pacios.

En Pacios, a 26 diciembre 1601, ante ídem (don Gregorio Vázquez de Parga). Pedro del Hoce, de Begonte, vendió al Gaspar dos fanegas de heredad en el agra da Paxe.

CERDEIRAS, Archivo del Pazo de Souto, Índice de Escrituras del Archivo de Souto, n. ${ }^{\circ}$ 678, extr. 
1603, febreiro, 24. Gaibor.

En Gaibor, a 24 febrero 1603, ante Pedro do Mato, escribano. Juana Díaz de Saabedra, viuda de Pedro López de Rábade, Gaspar López Vaamonde, de Trobo, hicieron cambio: la dicha Juana Díaz dio al Gaspar López dos piezas de heredad sitas en las cortiñas do Vilar, y otra pieza de heredad sita en Costoya; y el Gaspar da cinco piezas de heredad, incluso un prado de segar, sito en los prados da Vila. CERDEIRAS, Archivo del Pazo de Souto, Índice de Escrituras del Archivo de Souto, n. ${ }^{\circ} 770$, extr.

\section{4}

1603, novembro, 18. Pacios.

En Pacios, a 18 noviembre, 1603, ante don Gregorio Vázquez de Parga. Domingo de Pígara y su mujer vendieron a Gaspar López de Baamonde una 8. ${ }^{\mathrm{a}}$ parte de la casa y lugar da Areosa, la 8. ${ }^{\mathrm{a}}$ de un $4 .^{\circ}$ de molino en 84 reales de plata.

CERDEIRAS, Archivo del Pazo de Souto, Índice de Escrituras del Archivo de Souto, n. ${ }^{\circ}$ 1266, extr.

55

1604, marzo, 1. Santa María de Trobo.

Gaspar López de Vaamonde, veciño de Trobo, redime por 26 ducados e 4 reais e medio por escrituras a Catalina González e ó seu segundo marido Bartolomé Blanco, o lugar da Igrexa, segundo o tiña anteriormentes por foro Pedro da Cerdeira, seu primeiro marido, de don Fernando das Seixas, polo que pagaba de renda media fanega de pan e unha galiña; e un prado de unha fanega nos da Seara.

LUGO, Archivo de Gaibor, leg. 7, n. ${ }^{\circ}$ 54, papel, copia notarial, castelán, letra procesal.

1606, xullo, 9. Carballeira.

En Carballeira, feligresía de San Gillao de Mourence, a 9 julio mil seiscientos seis, ante don Gregorio Vázquez de Parga, de San Martín de Pacios. María Oanes, viuda de Basco Fernández de <a>quella feligresía, vendió a Gaspar López de Vaamonde el casar do Bautiro, y medio cuarto del molino nuevo en el río da Toupeira. CERDEIRAS, Archivo del Pazo de Souto, Índice de Escrituras del Archivo de Souto, n. ${ }^{\circ}$ 1067, extr. 
1606, agosto, 8. Insua.

En Ynsua, a 8 de agosto 1606, ante don Gregorio Vázquez de Parga, de San Martín de Pacios. Gaspar López de Vaamonde, por sí y su muger dotó a su hija Ysabel en 300 ducados y ropas, para casarse con Juan Vázquez.

CERDEIRAS, Archivo del Pazo de Souto, Índice de Escrituras del Archivo de Souto, n. ${ }^{\circ} 1059$, extr.

1608, xuño, 13. Saavedra.

En Saabedra, a 13 junio, 1608, ante don Bernardo de Barral, escribano de la Audiencia. Gaspar López Baamonde y Rodrigo do Barrio, y su hijo, de dicha feligresía, digeron que siendo sucesor el Rodrigo de un vínculo poseído por Fernando de Martul, que había vendido al Gaspar seis celemines vinculares en el cortiñal da Canle, en el da Viña, y en el agra de Paxe, y habiendo acerca de ello puesto pleito, transigíendolo el Gaspar dio al Rodrigo y sucesores otros 6 celemines en dicha agra y en el cortiñal do Pacio.

CERDEIRAS, Archivo del Pazo de Souto, Índice de Escrituras del Archivo de Souto, n. ${ }^{\circ}$ 664, extr.

\section{9}

1611, xaneiro, 29. Lugo.

En Lugo, a 29 enero 1611, ante don Juan Sanjurjo. El Cabildo Catedral aforó a Gaspar López Baamonde, y su mujer, de Trobo, la mitad del coto de Romariz en renta anual de 8 fanegas y media de centeno.

CERDEIRAS, Archivo del Pazo de Souto, Índice de Escrituras del Archivo de Souto, n. ${ }^{\circ}$ 1259, extr. LUGO, Archivo Catedralicio, Tumba de Escrituras, fol.78r. y 78b., cita.

\section{0}

1616, xuño, 9.

Testimonio de escritura en 1616 ante don Gregorio Vázquez de Parga, por la que Gaspar López de Vaamonde y su mujer de una parte, y de la otra Ynés Fernández de Lago, viuda de Basco Villet, de Felmil, dijeron que para casarse Pedro Tenrreiro y 
Lago con Catalina López de Baamonde, la Ynés mejoró a su hijo en 3 . $^{\circ}$ y 5. , y los Gaspar y su muger dotaron a su hija en 250 ducados en pan de renta en Pígara.

CERDEIRAS, Archivo del Pazo de Souto, Índice de Escrituras del Archivo de Souto, n. ${ }^{\circ} 1068$, extr. LUGO, Archivo de Gaibor, Inventario de Escrituras del Archivo de Gaibor, Leg. 6, n. ${ }^{\circ}$ 33, extr., fol.68r.

Observacións: O regesto do «Inventario de escrituras de Gaibor» dí o seguinte: «Escritura de dote en favor de Pedro Tenreiro de Lago otorgada en nueve de junio de 1616 por Gaspar López de Vaamonde y Constanza López de Parga, su mujer, vecinos de esta parroquia [Santa María de Trobo], y diligencias practicadas para su cobranza, resultando después de varias contestaciones, tener que pagarle aquél y las rentas atrasadas».

1621, novembro, 21. Trobo.

En Trobo, a 21 noviembre 1621, ante don Pedro Lozano, de Villalva. Pedro Tenreiro de Lago, de Felmil, da carta de pago a favor de su suegro, Gaspar López de Baamonde, de 250 ducados prometidos en dote a su hija Catalina para casarse con el Tenreiro.

CERDEIRAS, Archivo del Pazo de Souto, Índice de Escrituras del Archivo de Souto, n. ${ }^{\circ} 1035$, extr.

1622, abril, 3. Trobo.

En Trobo, a 3 de abril, 1622, ante don Antonio López. Antonio de Paderne, de Betanzos, vendió al Gaspar 7 fanegas de pan de renta anual sobre los lugares de Martín, en Trobo, en 85 ducados.

CERDEIRAS, Archivo del Pazo de Souto, Índice de Escrituras del Archivo de Souto, n. ${ }^{\circ}$ 640, extr.

63

1623, maio, 29.

Testimonio de varios pedimientos, y de cesión hecha a 29 mayo, 1623, ante don Pedro Lozano, por Gaspar López de Baamonde, a favor de su hijo Sevastián, de 7 fanegas de pan de renta que comprara a Antonio de Paderne Rebellón, de la ciudad de Betanzos, sobre los lugares de Martín, según escritura que pasó ante Antonio López Moro.

CERDEIRAS, Archivo del Pazo de Souto, Índice de Escrituras del Archivo de Souto, n. ${ }^{\circ}$ 1056, extr. 


\section{4}

1630, marzo, 10. Santa María de Trobo.

Documento privado mediante o cal Sebastián do Monte permuta con Gaspar López de Vaamonde dando iste unha leira de media fanega na agra do Barreiro, $e$ rescibindo de aquíl en compensación dúas pezas de media fanega de pan, unha de celemín e medio nisa mesma agra, e outra de medio celemín na agra de Milite, xunto á brea do Porto a Malde.

LUGO, Archivo de Gaibor, leg. 7, n. ${ }^{\circ}$ 80, papel, orix., castelán, letra bastardilla española.

\section{5}

1633, abril, 5. Trobo.

En Trobo, a 5 abril 1633, ante Gabriel do Rego, vecino de la feligresía de San Jurjo de Río Aveso. El Capitán Sebastián de Baamonde y Parga, vecino de Trobo, por sí, por su hermano Bartolomé López Vaamonde y el licenciado Manuel de Baamonde y Parga, de la ciudad de Betanzos, y Antonio López Moro, escribano del coto do Mato, Juan Vázquez, vecino de Casar y Pedro Tenrreiro, vecino de Felmil, todos por lo que les toca y en nombre de sus mujeres, hijas y herederos de Gaspar López Vaaamonde, otorgaron obligación de responder de la parte de la herencia que pudiese pertenecer a sus hermanos Gregorio Vázquez y Parga y Gaspar de Vaamonde y Parga, hijos legítimos de Gaspar de Baamonde y de su mujer, que se habían marchado al reino de Sevilla y reino del Perú, y se decía que habían fallecido, con el obgeto de poder hacer división y partija de la herencia fincable de sus padres.

CERDEIRAS, Archivo del Pazo de Souto, Índice de Escrituras del Archivo de Souto, n. ${ }^{\circ} 761$, extr. LUGO, AHP, Protocolos notariais de Gabriel do Rego, fol. 59r-60v, papel, orix., castelá, letra procesal.

66

[s. d.]

Papel simple por el que Francisco das Res da Cámara, de Pígara, vendió a Gaspar López Baamonde un leiro en el Vilar da Areosa de un celemín en 13 reales.

CERDEIRAS, Archivo del Pazo de Souto, Índice de Escrituras del Archivo de Souto, n. ${ }^{\circ} 629$, extr. 
[s. d.]

Papel simple por el que Sebastián do Monte, de Felmil, dio a Gaspar López Baamonde dos piezas, una en el agra do Barreiro, y la otra en el de Melite, sembradura media fanega; y el Gaspar le cedió otra pieza en aquella agra.

CERDEIRAS, Archivo del Pazo de Souto, Índice de Escrituras del Archivo de Souto, n. o 645, extr.

68

[s. d.]

Cédula simple de cambio de unos leyros entre Gaspar López Baamonde y Gonzalo Méndez, de Trobo.

CERDEIRAS, Archivo del Pazo de Souto, Índice de Escrituras del Archivo de Souto, n. ${ }^{\circ} 658$, extr.

69

[s. d.]

Cédula simple por la que Gaspar López Baamonde y Pedro Pechín repartieron entre sí una heredad.

CERDEIRAS, Archivo del Pazo de Souto, Índice de Escrituras del Archivo de Souto, n. ${ }^{\circ}$ 667, extr.

[s. d.]

Otra (cédula simple) por la que Rodrigo do Barrio, de Trobo, y su hijo, vendieron al Gaspar la cortina da Viña, de medio celemín, en 18 reales.

CERDEIRAS, Archivo del Pazo de Souto, Índice de Escrituras del Archivo de Souto, n. ${ }^{\circ} 668$, extr.

71

[s. d.]

Papel simple por el que Alberto de Castro, de Santa María del Castro, vendió al Gaspar la mitad tarreo de Cabecoy y la huerta que hiciera en el lugar de Martín. CERDEIRAS, Archivo del Pazo de Souto, Índice de Escrituras del Archivo de Souto, n. ${ }^{\circ} 682$, extr. 


\section{2}

[s. d.]

Cédula simplepor la que Gaspar López y Jácome do Bal trocaron dos cortiñas y dos leyros.

CERDEIRAS, Archivo del Pazo de Souto, Índice de Escrituras del Archivo de Souto, n. ${ }^{\circ}$ 685, extr.

\section{3}

[s. d.]

Papel simple por el que Gaspar López y Martín do Campo, transijiendo un pleito sobre quién había de llevar el prado de Paxe, que compraran a diversos vendedores, acordaron dividirlo por mitad, y dar el $2 .^{\circ}$ al $1 .^{\circ}$ un leyro en Paxe.

CERDEIRAS, Archivo del Pazo de Souto, Índice de Escrituras del Archivo de Souto, n. ${ }^{\circ} 688$, extr.

\section{4}

[s. d.]

Papel simple por el que Gaspar y Álbaro de Rábade, de Romariz, en Damil, trocaron ciertas piezas en Paxe y Baltar.

CERDEIRAS, Archivo del Pazo de Souto, Índice de Escrituras del Archivo de Souto, n. ${ }^{\circ}$ 696, extr.

\section{5}

[s. d.]

Trueque en que Gaspar de Baamonde dio a F. Rogica sesta parte del prado viejo de Requeijo; y éste aquél, un leiro en la Seara.

CERDEIRAS, Archivo del Pazo de Souto, Índice de Escrituras del Archivo de Souto, n. ${ }^{\circ}$ 1034, extr.

\section{6}

[s. d.]

Escritura de capitulación entre Gaspar López de Baamonde y Constanza Vázquez, y dote ofrecido por los padres de ella, y ofrecimiento del lugar de Pígara.

CERDEIRAS, Archivo del Pazo de Souto, Índice de Escrituras del Archivo de Souto, n. ${ }^{\circ}$ 1045, extr. 
[s. d.]

Testamento de Constanza Vázquez de Parga, muger de Gaspar López de Baamonde.

CERDEIRAS, Archivo del Pazo de Souto, Índice de Escrituras del Archivo de Souto, n. ${ }^{\circ} 1270$, extr.

78

[s. d.]

Aportación y confirmación de partijas de la fincabilidad de Gaspar de Baamonde y su mujer.

CERDEIRAS, Archivo del Pazo de Souto, Índice de Escrituras del Archivo de Souto, n. ${ }^{\circ}$ 1279, extr.

A Coruña e Trobo, 2006 
